\title{
Untersuchungen über die Resorption und Elimination des Quecksilbers.
}

\author{
Von \\ Dr. K. E. Lindén, \\ Chefarzt des Garnison-Krankenhauses in Helsingfors (Finnland).
}

Da die Methode, unlösliche Quecksilbersalbe zu injiciren, bei Behandlung der Syphilis immer mehr in Gebrauch gekommen ist, so ist in den letzten Jahren durchgehend das Streben der Syphilidologen gewesen, ein Quecksilberpräparat zu finden, das bei Behandlung der erwähnten Krankheit alle guten Eigenschaften in sich vereinigte, $d . \mathrm{h}$. bei der Injection die geringsten Schmerzen verursachte und mit der geringsten localen und allgemeinen Reaction die grösstmöglichste Garantie für eine schnelle und dauernde Heilung vereinigte, ohne schädliche Folgen für den Organismus hervorzurufen. Beim Suchen danach hat das eine Präparat dem anderen weichen müssen, ohne das bislang noch ein einziges alle Forderungen hat erfüllen und ausschliesslich dominirend bleiben können.

$\mathrm{Zu}$ den vielen Präparaten, welche so in letzter Zeit zur Anwendung kamen, gehören auch Thymol. Hg. acet., besonders aber Hg. Salicyl. Obgleich auch gegen diese Präparate berechtigte Einwendungen gemacht werden können, so dürfte doch ein Fortschreiten der Syphilistherapie durch ihre Einfiihrung nicht bestritten werden können und daher ein uäheres Studium derselben wohl am Platze sein. 
Bei der folgenden Untersuchung über die Aufnabme und Elimination des Quecksilbers sind die Analysen hauptsächlich nach Injection von Hg. Salicyl. ausgeführt und habe ich dieses Präparat nicht nur aus dem schon angedeuteten Grunde gewählt, sondern auch, weil die nach Quecksilber injectionen gemachten Untersuchungen verhältnissmässig wenige sind. Inzwischen dürfte nicht bestritten werden können, dass eine sichere Kenntniss über die Aufnahme des Quecksilbers und Elimination desselben aus dem Körper nebst allen damit verbundenen Umständen sowohl in theoretischer als auch noch mehr in praktischer Beziehung von grosser Bedeutung ist. Nicht am unwichtigsten ist, sich bei der jetzt imme: mehr zur Anwendung kommenden hypodermatischen Methode diese Umstände klarmachen und die für eine wirksame Behandlung nöthige Dosis näher feststellen zu können.

Um zu versuchen, eine in dieser Beziehung bestehende Lücke einigermassen auszufüllen, habe ich aus hauptsächlich nach Injection von $\mathrm{Hg}$. Salicyl. gemachten Analysen folgende Fragen zu beantworten gesucht: Wie schnell das Quecksilber nach einer oder mehreren Injectionen im Urine auftritt; wie lange es im Organismus verbleibt; ob bei Ausscheidung desselben eine Regelmässigkeit existirt? endlich, soweit es bei der angewandten Untersuchungsmethode möglich war, die ungefähre Menge des ausgeschiedenen Quecksilbers im Verhältniss zur angewandten.

Bevor ich auf diese Untersuchung übergehe, werde ich aus der mir zugänglichen Literatur eine kurze Uebersicht der früher in dieser Richtung gemachten Untersuchungen geben und dabei zur Beleuchtung der Frage die Aufmerksamkeit ausschliesslich darauf richten, was sie mit Hinsicht auf die Zeit für die Resorption und Elimination des Quecksilbers aus dem Organismus an die Hand geben, die grössere oder geringere Regelmässigkeit, mit welcher dieses vor sich geht, und die übrigen Umstände, welche diese Frage berühren.

Schon bei den älteren Verfassern kommen in Betreff der Ausscheidung des Quecksilbers aus dem Organismus die widerstreitendsten Angaben vor, und wurde die Elimination desselben oft mit der Darreichung von Jodkali in Zusammenhang 
gebracht. So hält nach Kussmaul ${ }^{1}$ ) Lorinser dafür, dass das Quecksilber jahrelang im Körper verbleiben könne, sofern nicht Jodkali zur Anwendung käme.

Michaelis erhielt noch 2 Monate nach Quecksilbergebrauch Quecksilberreaction aus dem Urin; im dritten Monat konnte er es nicht mehr nachweisen, trotzdem die Untersuchungen an Urin gemacht wurden, der während dreier Tage gesammelt worden war; doch hat er derartige Untersuchungen nur einmal ausgeführt.

Kussmaul ${ }^{2}$ ) gibt nur sehr spärliche Angaben über die Ausscheidung des Quecksilbers aus dem Organismus. Bei einem Gewerbemercurialismus fand er 8 Tage nach Aufhören der Arbeit nur wenig Quecksilber, trotzdem die Analyse aus einer grossen Urinmenge gemacht wurde. In einem anderen ähnlichen Falle konnte gar kein Quecksilber nachgewiesen werden, obgleich noch ein halbes Jahr später Niere und Leber bei der Obduction grosse Mengeu davon enthielten. Er nimmt daher an, dass das Quecksilber nicht immer mit dem Urin abgeht, wenn es sich auch im Organismus findet.

Derselben Ansicht ist auch Overbeck, ${ }^{3}$ ) welcher dafür hält, dass die Quecksilberausscheidung aus dem Körper grossen Schwankungen unterworfen ist, einem Steigen und Fallen, ja mitunter für eine Zeit ganz und gar verschwunden sein kann. In Hinsicht auf das Verharren des Hg. im Körper kommt er zu demselben Resultat wie Waller, dass die Quecksilberausscheidung aus dem Organismus langsam vor sich geht, jedenfalls Monate dauert, unter gewissen Umständen bis 7 Monate und noch länger. Das Verweilen des Quecksilbers hängt nach ihm nicht davon ab, dass dem Körper eine grosse Menge desselben zugeführt wird, sondern von individuellen Verhältnissen.

Nach Landsberg ${ }^{4}$ ) hätte Schneider nach längerem Quecksilbergebrauch dasselbe stets auch nach Beendigung der

l) Kussmaul. Untersuchungen über den constitutionellen Mercurialismus. 1861 . p. 411.

2) 1. c. p. 413 .

3) Overbeck. Mercur und Syphilis. Berlin. 1861. p. 230.

4) Landsberg. Ueber Ausscheidung des Quecksilbers aus dem Organismus. Breslau. 1886. p. 17. Inaug. Dissert. 
Cur im Urine gefunden; so hat er es nach innerlicher Behandlung constant während der ersten 8 Tage nachweisen können, in einem Falle noch 4 Wochen und in einem anderen Falle noch 6 Wochen nach beendeter Behandlung. Die Untersuchungen wurden :am Urin gemacht, der während 4 Tagen gesammelt war. Waren einige Monate seit der Cur verflossen, so suchte er vergebens Quecksilber im Urine.

Hallopea ${ }^{1}$ ) bespricht von Mayençon und Bergeret gemachte Untersuchungen, wo nach einer einzigen Dosis Sublimat 0.01 der Urin während der ersten 24 Stunden Quecksilber enthielt, aber später keine Spur mehr davon entdeckt werden konnte. Ebenso führt er an, dass Byosson bei einer subcutanen Injection von 0.02 Sublimat nach 2 Stunden Quecksilber im Urin fand, nach, 4 Stunden im Speichel, nach 24 Stunden aber die Ausscheidung abgeschlossen war. Währt die Behandlung dagegen längere Zeit und werden grössere Dosen dem Organismus zugeführt, so kann nach Hallopea u die Elimination des Quecksilbers auf mehrere Monate, ja mitunter sogar auf Jahre verlängert werden.

Schmidt, ${ }^{2}$ ) der seine Untersuchungen an 14 Fällen machte, wovon 7 mit Sublimatinjectionen behandelt wurden, 6 mit Einreibung von Ung. ciner. und 1 mit Calomel innerlich, fand nach jeder Behandlung Quecksilber im Urin. Beim Vergleich der hypodermatischen und endermatischen Quecksilberbehandlung fand er, dass bei Sublimatinjectionen das Quecksilber viel schneller und in bedeutend grösserer Menge in den Organismus übergeht als nach der Inunctionscur. Calomel innerlich gegeben, siët er, was Quantität und Zeit seines Auftretens im Urin betrifft, als zwischen beiden vorhergehenden Methoden stehend an. So fand er nach täglicher Injection von $1 / 5$ Gr. Sublimat am nächsten Tage Quecksilber. Nach innerlicher Behandlung mit Calomel fand sich Hg. am 4. Tage im Urin und bei Anwendung von grauer Salbe $2-4 \mathrm{Gr}$. gaben die Analysen in einem Falle am 6. und 7. Tage ein negatives

1) Hallopeau. Du mercure action physiologique et therapeutigue. Paris. 1878. pag. 59.

2) Ein Beitrag zur Frage der Elimination des Quecksilbers aus dem Körper. Inaug. Dissert. Dorpat. 1879. 
Resultat, erst am 13. und 28. Tage ein positives. In einem anderen Falle fand sich am 8. Tage kein Quecksilber, konnte aber am 17. Tage im Speichel nachgewiesen werden; in einem 3. Falle konnte noch am 5. Tage kein Quecksilber nachgewiesen werden, wohl aber am 11. Vor der Behandlung und in den Zwischenzeiten sind keine Untersuchungen gemacht worden, daher geht also aus diesen Fällen nicht hervor, wann die frühste Quecksilberausscheidung begann. Ebenso sind keine Untersuchungen über seine Remanenz gemacht worden.

Im Jahre 1880 gaben $\mathrm{Vajda}$ and $\mathrm{Paschk}$ is ${ }^{1}$ ) eine recht umfangreiche Arbeit, die Frucht mehrjähriger Studien, heraus. In derselben werden Quecksilberanalysen ïber 201 Fälle mitgetheilt; da aber in 160 Fällen nur eine einfache Analyse gemacht wurde, in 28 Fällen 2 , in 6 Fällen 3 und in 7 Fällen 4 oder mehrere Analysen so ist einzusehen, dass der Analysen allzuwenige sind, um darauf sichere Schlusssätze aufbauen zu können, und die Resultate, zu denen Vajda und Paschkis gelangen, nicht immer wohl begründet sind. So nehmen sie an, ${ }^{2}$ ) dass das Quecksilber sich ebenso häufig im Urin findet, der mehrere Jahre nach der Bebandlung untersucht wird, wie in dem in der ersten Woche nach derselben entnommenen, und dass das Quecksilber bis 13 Jahre uach abgeschlossener Behandlung im Organismus verbleiben könne.

In Hinsicht auf die Aufnahme des Quecksilbers und seine Ausscheidung aus dem Körper ist nach ihnen die Qualität von grösserer Bedeutung als die Quantität, da die leicht löslichen Verbindungen im Allgemeinen leichter durch das Gefässsystem passiren; demnächst wird die Bedeutung der Quantität hervorgehoben, doch hat kein directes Verhältniss zwischen der angewandten Quecksilbermenge und seiner Remanenz nachgewiesen werden können. In Uebereinstimmung mit früheren Verfassern fanden sie, dass die Quecksilberausscheidung sehr unregelmässig vor sich geht. Von 68 während der Behandlung untersuchten Fällen konnte nur in 39 Quecksilber im Harne

I) Ueber den Einfluss des Quecksilbers auf: den Syphilisprocess. Wien 1880.

2) l. c. p. 285 . 
nachgewiesen werden, und in den nach der Behandlung gemachten Untersuchungen wurden in einem Theil der Fälle während der ersten Woche negative Resultate erzielt, während wieder noch 8, 12 und 13 Jahren nach abgeschlossener Bebandlung positive Resultate gezeigt werden konnten.

Um den Einfluss der Qualität des Quecksilbers auf seine Ausscheidung zu prüfen, wurden die Quecksilberbestimmungen nach Anwendung der meist gebräuchlichen Präparate gemacht, und daraus der Schluss gezogen, dass das Quecksilber am frühsten nach Gebrauch von Decoct. Zittmanni ausgeschieden wird, nämlich schon am folgenden Tage. Dieser Schluss wird auf Grund zweier mit erwähntem Decoct behandelter Fälle, wobei nur zwei Untersuchungen gemacht wurden, und aus 3 nach Sublimatinjectionen in dreien Fällen gemachten Analysen gezogen. In keinem Falle sind die Analysen indessen nach der ersten Injection gemacht, wo sich möglicher Weise schon Quecksilber im Urine fand, sondern frühestens nach der zweiten. Bei Untersuchungen, welche nach Calomelinjectionen, einmal in jedem Falle (ausser in einem, wo zwei Analysen ausgeführt wurden) gemacht wurden, wurde nur 5mal in 13 Fällen Quecksilber im Urine constatirt und dann frühestens 10 Tage nach der letzten Injection. Die Zahl der Injectionen betrug gewöhnlich 3 und die Grösse der Dosis 0:35. Wo die Analyse ein negatives Resultat ergab, war es in den meisten Fällen zur Abscedirung gekommen, aber auch, wo kein Abscess eintrat, wurde am 1. und 5. Tage nach der Injection ein negatives Resultat erhalten. Sie schliessen daraus, dass nach Calomelinjectionen das Quecksilber später im Harne auftritt als nach den erstgenannten Präparaten.

Nach innerem Gebrauch von Sublimat trat die Ausscheidung erst nach 11 und 12 Tagen, nach Verbrauch von $11 \mathrm{Ccm}$. Sublimat auf. In anderen Fällen fand sich auch nach einmonatlichem Gebrauch desselben kein Quecksilber vor.

Bei der Schmiercur mit Ung. hydrarg. konnte Quecksilber in zwei Fällen erst am 3. Tage nach der zweiten Einreibung entdeckt werden, in einem 3. Falle erst nach der 7. Einreibung:

Bei Inunctionscur mit Ung. hydrarg. konnte Quecksilber während und nach der Behandlung häufiger nachgewiesen 
werden als bei Anwendung anderer Präparate. Nach Sublimatinjectionen dagegen fand sich Quecksilber häufiger (als bei der Schmiercur) während der Behandlung, dafür selten nach der Behandlung.

Mit Bezug auf den chronischen Verlauf der Syphilis halten $\mathrm{Vajda}$ und Paschkis die Inunctionscur für die passendste Behandlungsmethode, da man von ihr die andauerndste Wirkung erwarten kann, dagegen werde die Schmiercur von den leichtlöslichen Quecksilbersalzen übertroffen, wo es sich um Hervorrufung einer schnellen Wirkung handelt.

Den Vergleich zwischen den verschiedenen Behandlungsmethoden gründen sie, wie oben ersichtlich, auf ein recht beschränktes Material, speciell was die Quecksilberinjectionen betrifft.

Oberlände $\mathbf{r}^{\mathbf{1}}$ ) kommt in seinen Untersuchungen über die Ausscheidung und Remanenz des Quecksilbers zum Schluss, dass dasselbe sogar noch 190 Tage nach abgeschlossener Quecksilbercur im Urine nachzuweisen ist, und dass bei der Ausscheidung Exacerbationen und Remissionen sowie vollständige Pausen vorkommen. Diese können 8-10 Tage dauern, und in kürzeren Zeiträumen von 12 bis 24 Stunden.

In Uebereinstimmung mit Ob e r länd er meint Schuster, ${ }^{2}$ ) dass eine Regelmässigkeit in der Ausscheidung des Quecksilbers nicht nachzuweisen ist, sondern dass diese mit langen quecksilberfreien Pausen vor sich geht. Im Gegensatz zu Vajda und Paschkis wieder fand er nicht so häufig Quecksilber im Harne, auch hat er keine so lange Remanenzzeit beobachtet wie diese. Von 52 Urinuntersuchungen, hauptsächlich nach Inunctionen, gaben nur 20 ein positives Resultat, die übrigen ein negatives. Am frübsten wurde Quecksilber 7, 8 und 12 Tage nach der Behandlung angetroffen.

Die von $\mathrm{Vajda}$ und $\mathrm{Pasch}$ is beobachtete lange Remanenzzeit beruht nach Schuster nicht auf dem Quecksilber, das vor Jahren während einer Cur dem Organismus zugeführt wurde, sondern auf dem durch die Respiration dem Patienten

1) Vierteljahrschrift für Dermatologie und Syphilis. 1880. p. 512.

2) Vierteljahrschrift für Dermatologie und Syphilis. 1882. 
zugeführten, der lange in einem syphilitischen Krankenhause gelegen habe.

Gegen alle oben angeführten Untersuchungen kann jedoch mit $\mathrm{Nega}^{1}$ ) der Einwand erhoben werden, dass in den meisten Fällen nur eine einzige Analyse gemacht worden ist, und dass also, wo ein negatives Resultat erzielt wurde, damit noch nicht gesagt ist, dass eine Analyse nach der Cur nicht ein positives Resultat hätte geben können. Nega hat auch im Gegensatz zu Schuster bei mercurialer Cur Quecksilber im Urine nachweisen können. Er hat nämlich bei allen Patienten, die einer längeren Behandlung unterlagen (12-24 Inunctionen), durch wiederholte Untersuchungen die Anwesenheit des Quecksilbers im Urine während der Behandlung dargelegt. Auch wäbrend der drei ersten Monate nach der Cur ist es ihm geglïckt, $\mathrm{Hg}$. im Urine nachzuweisen, vorausgesetzt freilich, dass grössere Mengen eingerieben waren.

Seine Untersuchungen wurden hauptsächlich nach Einreibungen von sapo niercur., ung. cin. und Quecksilberoleat gemacht. Nach Einreibung von sap. mercurial. an 8 Patienten, gaben von 66 Untersuchungen 18 ein negatives Resultat; in der Mehrzahl der Fälle trat das Quecksilber erst nach 2, 3 oder 5 Einreibungen auf.

Nach Einreibung von grauer Salbe an 9 Patienten erbielt er in 47 Fällen ein positives und in 3 Fällen ein negatives Resultat. Von 10 einen Monat nach der Behandlung gemachten Analysen gaben 6 positive und 4 negative Resultate.

Bei Einreibungen von Quecksilberoleat gaben ron 210 Analysen 124 positives und 86 ein negatires Resultat.

Bei der cutanen Methode kann das Quecksilber ebenso wie nach der Ixjectionsmethode schon nach 24 Stunden im Harne gefunden werden, und geht also die Resorption durch die Haut recht schnell. Häufig hat es jedoch nicht vor der 2., 3. oder 5. Einreibung nachgewiesen werden können, wahrscheinlich weil die Resorption nach dieser Methode allmälig

1) Vergleichende Untersuchungen über die Resorption und Wirkung: verschiedener zur cutanen Behandlung verwandter Quecksilberpräparate. 1884. p. 66 . 
vor sich geht und die Quantitäten zu gering sind, um entdeckt werden zu können, wogegen bei der Injection grössere Quantitäten schnell in die Circulation gebracht werden.

$\mathrm{Zu}$ demselben Resultat wie letztgenannter Verfasser kommt mit Bezug auf Quecksilberaufnahme und -ausscheidung

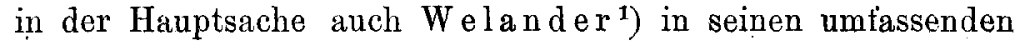
und sorgfältig ausgeführten Untersuchungen 1886. Er hat das Quecksilber, in welcher Form es auch dem Körper zugeführt wurde, innerhalb des ersten Tages nachweisen können. Doch gab es auch Fälle, wo bei Einreibungen mit ung. Hg. bis zum 4., ja sogar bis zum 8. Tage, trotz täglicher Einreibung, kein Quecksilber gefunden werden konnte. Dagegen wurde nach Quecksilberinjectionen mit Sublimat, sowie an 4 Patienten mit $\mathrm{Hg}$. formamid. und an 1 Patienten mit Calomel schon nach 1 und $1 \%$ Stunden in ganz beträchtlicher Menge Quecksilber ausgeschieden. Nach Calomelinjection, $0 \cdot 20$, wurde jedoch nach 8 Stunden noch kein Quecksilber angetroffen, sondern erst nach ungefähr 18 bis 20 Stunden, und war die Menge nach 6 Tagen sehr bedeutend. Bei allen späteren Untersuchungen zeigte sich, dass bei dieser Behandlung das Quecksilber sich in grösserer Menge vorfand als nach jeder anderen und noch einen Monat nach der letzten Injection auftrat. Auch nach Sublimatinjectionen kann das Quecksilber noch nach einem Monat nachgewiesen werden und nach $\mathrm{Hg}$. formamid. nach 2 Monaten.

Auf Grund seiner Untersuchungen kommt Welander zu dem Schlusse, dass das Quecksilber bei Injection in einer dieser Formen schnell und in grosser Menge absorbirt wird.

$\left.\mathrm{Kopp}{ }^{2}\right)$ dagegen hat, wenn 5 Wochen nach einer Bebandlung mit $\mathrm{Hg}$. formamid. verflossen waren, kein Quecksilber mehr im Harne nachweisen können.

Auch bei innerlichem Gebrauch fand Welander im Urine schon nach 4 and 7 Stunden Quecksilber. Obgleich er

1) Nordiskt Medicinsut Arkiv. Band 18, 1886. Quicksilfrets upptagande och afskiljande ur menniskokroppen.

$\left.{ }^{2}\right)$ Ueber Behandlung der Syphilis mit subcutanen Injectionen von Hg. Formamid. Vierteljahrschrift für Dermatologie und Syphilis. 1885. 
die Zahl seiner Untersuchungen für zu gering ansieht, um zu sicheren Schlusssätzen zu berechtigen, so findet er doch, dass viel dafür spricht, dass die Quecksilberausscheidung aus dem Körper am schnellsten bei Einführung desselben in Form der subcutanen Injection beginnt, und ist daher nach ihm die Injectionsmethode die sicherste, wo eine schnelle Wirkung des Quecksilbers bezweckt wird, denn die schnelle Elimination beweist die schnelle Absorption.

Die periodische oder unausgesetzte Ausscheidung des Quecksilbers betreffend, kommt er im Gegensatz zu den meisten früberen Verfassern zu der Ueberzeugung, dass es regelmässig ausgeschieden wird, so lange es sich im Körper findet, denn mit wenigen Ausnahmen hat er bei seinen Untersuchungen immer Quecksilber in solchen Fällen gefunden, wo man Grund hatte, das Vorhandensein desselben anzunehmen. Die widersprechenden Angaben betreffs der Absorption und Elimination des Quecksilbers beruhen nach ihm auf mangelhaften Untersuchungsmethoden.

Auch in Hinsicht auf die Quantität des ausgeschiedenen Quecksilbers will er eine gewisse Regelmässigkeit annehmen; denn obgleich mit der von ihm angewandten Untersuchungsmethode keine absoluten Bestimmungen in Frage kommen können, so hält er sich doch durch die angewendete approximative Berechnung für berechtigt, den Schlusssatz zu ziehen, dass die Quantität des ausgeschiedenen Quecksilbers in directer Proportion zu der im Körper befindlichen steht.

Je früher nach Schluss der Behandlung er die Analyse machte, desto grösser fand er stets die ausgeschiedene Quecksilbermenge. Dass das Quecksilber bisweilen schneller, bisweilen langsamer ausgeschieden wird, beruht nach $W$ eland e $r$ darauf, wie gross die dem Körper zugeführte Quantität gewesen ist. Eine kleinere Quantität wird schneller ausgeschieden, eine grössere langsamer und die Qualität dürfte dabei keine besondere Rolle spielen.

In Hinsicht auf die Zeit, welche das Quecksilber im Körper verweilen kann, meint er, dass es in der Regel 4-6 Monate verbleibt, in 2 Fällen hat er es noch nach 7 Monaten gefunden. 
So übereinstimmend die früheren Verfasser in ihren das Unbeständige der Quecksilberausscheidung aus dem Körper betreffenden Angaben waren, ebenso iibereinstimmend scheinen die in letzter Zeit in Hinsicht auf die Constanz und Remanenz derselben gemachten Untersuchungen $\mathrm{zu}$ sein. So sind auch Landsberg ${ }^{1}$ ) und Watraszewski zu Resultaten gelangt, welche sich in der Hauptsache Nega und Welander anschliessen.

Die Untersuchungen des ersteren, 160 Analysen in 22 Fällen, meist nach Calomelinjectionen ausgeführt, zeigen, dass sich bei Behandlung mit den gewöhnlichen Dosen beständig Quecksilber findet, derart, dass 16-24 Stunden nach einer Injection von 0.20 Calomel im Urine Quecksilber nachgewiesen werden kann, dessen Menge während des 3. und 5. Tages ihr Maximum erreicht, auf welchem sie sich dann, mit kleinen Abweichungen, mehrere Wochen erhält. Dann wird die Quantität geringer mit grösseren Schwankungen, bis es nicht mehr nachgewiesen werden kann. Sollten, so meint er, erneuerte Injectionen gemacht werden, wenn die Ausscheidung noch constant ist, so üben sie keinen Einfluss auf das Absonderungsverhältniss, sondern nur auf die Remanenz des Quecksilbers. Es wird eine längere Zeit beständig ausgeschieden; werden aber die Injectionen später gemacht, wenn die Quecksilberquantität schon geringer ist, so steigt sie wieder auf das Maximum.

Mit Bezug auf die Remanenz fand er in einem Falle nach 6 Injectionen noch 2 Monate später Quecksilber, in einem anderen Falle noch nach 10 und 13 Monaten, wenngleich dann nur in geringer Menge; bei einigen. Untersuchungen fehlte es ganz und gar.

Was nun speciell Hg. salicyl., seine Resorption und Elimination betrifft, so habe ich in der Literatur nur eine Veröffentlichung von Lew i ${ }^{2}$ ) gefunden, 31 Analysen an 5 Patienten umfassend, wo er nach Injection von $0.05 \mathrm{Hg}$. salicyl. innerhalb

1) $1 . \mathrm{c}$.

$\left.{ }^{2}\right)$ Ueber den Nachweis der Ausscheidung des Quecksilbers aus dem Organismus durch den Harn. Inaug. Dissertation. 1889. 
48 Stunden und bisweilen noch früher Quecksilber im Urin fand; die exsten Tage nur in geringer Menge, die später schnell zunimmt und dann einige Zeit (einige Tage) hindurch constant nachgewiesen werden kann.

Auch $\mathrm{B} \ddot{\mathrm{h} \mathrm{hm}}{ }^{1}$ ) hat einige Untersuchungen über die Löslichkeits- und Resorptionsverhältnisse des $\mathrm{Hg}$. salicyl. gemacht und gefunden, dass dasselbe in dieser Beziehung dem Calomel nahe steht. Bei Versuchen an Thieren constatirte er eine sehr reichliche Resorption von $\mathrm{Hg}$. salicyl. und beim Vergleich mit ron Schmidt und Winternitz an Calomel ausgeführten Untersuchungen kommt er zum Schluss, dass beim innerlichen Gebrauch von Hg. salicyl. die Resorption unvollständig, aber doch recht bedeutend ist, wahrscheinlich reichlicher als bei nicht giftigen Dosen ron Calomel. Die letztgenannten Verfasser haben auch bei Einreibungen grosse Mengen ron Quecksilber gefunden, aber erst nach längerem Gebrauch derselben.

Die meisten Untersuchungen, welche zur Prüfung des Quecksilbergehaltes im Organismus gemacht wurden, sind mit einigen kleinen Aenderungen und Modificationen nach der Ludwig-Fürbringer'schen Methode ausgeführt; der Hauptgang ist für alle wesentlich derselbe gewesen. Die Analyse wird nach dieser Methode bekanntlich so ausgeführt, dass in $500 \mathrm{Ccm}$. Urin 0.25 Gr. Lametta hineingethan wird. Der Urin wird auf $60-70^{\circ}$ erwärmt und muss dann längere Zeit stehen. Darauf wird er abgegossen und die Lametta wird in beissem Wasser, Alkohol und Aether gewaschen, getrocknet und in ein Glasrohr gethan, dessen beide Enden zu Capillarröhren ausgezogen sind. Wird nun die die Lametta enthaltende Mittelpartie der Röbre erwärmt, so sublimirt das Quecksilber an den Wänden der Röhre. Ein kleines Korn Jod wird in die Capillarröhre gethan und nach vorsichtiger Erwärmung bildet sich an der Röhre ein rother Ring von Quecksilberjodid.

1) Quantitative Untersuchungen über die Resorption und Ausscheidung des Quecksilbers bei jnnerlicher Verabreichung von Hg. salicyl. Zeitschrift für Physiologische Chemie. Bd. XV. 1. Heft. 1891. 
Untersuchungen über d. Resorption u. Eliminat. des Quecksilb. 183

Schridde modificirt die Methode derart, dass er in einer gleich dicken, $12 \mathrm{Cm}$. langen und $1 \mathrm{Cm}$. breiten Röhre, deren eines Ende zugeschmolzen ist, die Röhre mit der darin. liegenden Lametta auf einem Bunsen'schen Brenner erwärmt, diese dann hinauswirft und auf den heissen Boden ein kleines Körnchen Jod hineinwirft. Diese auf Ueberführung des Quecksilbers in eine Jodverbindung basirte Methode scheint sehr zarter Natur zu sein, denn wird zufälligerweise mehr Jod hineingethan als nöthig ist, so kann leicht, wie $\mathrm{Nega}$ erfuhr, bei Verflüchtigung des Ueberschusses auch das Quecksilber leicht entweichen und so die ganze Analyse riskirt werden. Ich habe daher für meine Untersuchungen die Allmén'sche von Schillberg modificirte Methode gewählt, die auch von Welander befolgt und in den im Nordiskt Med. Arkiv 1886 Band 18 veröffentlichten Untersuchungen beschrieben ist, und welche Methode von ihm für die beste und die sichersten Resultate gebende gehalten wird.

Diese Methode basirt wie die erste aut Fällung des Quecksilbers auf elektrolytischem Wege auf Metall, von welchem es dann durch Erwärmen freigemacht und darauf in eine geschlossene Glasröhre aufgenommen wird. Nach dieser Methode kann das Quecksilber nicht nur qualitativ, sondern auch annäherungsweise quantitativ bestimmt werden, da vermittelst des Mikroskopes auch minimale Quantitäten nachgewiesen werden können.

Ich werde nun eine kurze Darstellung der Methode geben, die Welander in oben erwähnter Arbeit beschreibt.

Die zur Untersuchung bestimmte Urinmenge, gewöhnlich $300 \mathrm{Ccm}$., wird mit Natronlauge und etwas Honig versetzt, in einem Glaskolben erhitzt und muss $1 / 4$ Stunde über einer Gastlamme kochen. Der Inhalt des Kolbens wird in ein Decantirglas entleert. Nachdem sich die Fällung abgesetzt, wird die klare Flüssigkeit abgegossen und der Bodensatz in einen kleineren Kolben aufgenommen. Der grössere Kolben wird mit etwas Salzsäure nachgespült, um möglicherweise nachgebliebene Reste der Fällung aufzulösen, und die Spülflüssigkeit wird zum Niederschlage in den kleineren Kolben gegossen. In den Kolben wird ein vorher gegliuhter Kupferdraht von $3 \mathrm{Cm}$. Länge und 
$5 \mathrm{Mm}$. Dicke gethan; der Inhalt wird bis zum Kochen erhitzt und der Kolben mit einem Kork verschlossen, in den der Länge nach eine feine Rinne geschnitten ist, und dann in eine Ofennische gesetzt, wo er $1 \frac{1}{2}$ bis 2 Tage bei einer Temperatur von $45-65^{\circ} \mathrm{C}$. stehen muss. Der Kupferdraht wird darauf herausgenommen und mit Wasser gespült; finden sich an ihm möglicherweise Urin- und Färbesubstanzen abgesetzt, so wird er, um ihn davon zu befreien, mit Natronlauge gekocht, worauf er vorsichtig an Fliesspapier abgetrocknet und in ein feines ausgezogenes Glasrohr mit für ihn abgepasstem Lumen gethan wird. Die Glasröbre wird aus grobkalibrigen Röhren, die aus leichtschmelzendem, gleichmässigem und blasenfreiem Stoff bestehen, über einer Spiritus- oder Gasflanme ausgezogen, dann an beiden Enden zugeschmolzen und rorsichtig erwärnt, worauf das Quecksilber sublimirt und sich im Röhrchen dicht vor dem Ende des Metalldrahtes absetzt. Es zeigt sich hier unter dem Mikroskope als grössere und kleinere undurchsichtige Kugeln. Je kleiner die Kugel ist, desto dunkler erscheint sie und desto weniger tritt an ihr der Metallglanz hervor; an den grösseren Kugeln dagegen bemerkt man deutlich eine bleigraue Metallfarbe und einen Lichtreflex in der Mitte der Kugel und an ihrer vorderen Seite. Diese Quecksilberkugeln placiren sich bäufig in den gelblichen Oeltropfen, die an der inneren Seite der Röhre zu sehen sind, wodurch ihre Conturen schärfer und also leichter zu entdecken sind; aber auch in den grösseren oder kleineren Wassertropfen sind oft kleine Quecksilberkügelchen zu sehen. Eine Einstellung der vorderen Seite der Röhre erleichtert auch in gewissem Grade die Entdeckung derselben, da aber die Kügelchen bei Weitem nicht immer auf einer Stelle versammelt sind, sondern im Gegentheil an verschiedenen Stellen der Röhre verstreut, so ist es nothwendig, durch Verschiebung und Rotation der Röhre so viele verschiedene Theile derselben als möglich zur Beobachtung zu bringen. Durch. diese Art der Arbeit kann nicht nur eine qualitative Bestimmung gemacht werden, sondern es kann auch durch die Grösse und Menge der Kugeln eine quantitative Abschätzung erhalten werden.

Da die beiden Enden der Glasröhre gewöhnlich von verschiedener Dicke sind, so kann die Erwärmung vom schmälerèn 
Ende ausgehen zum dickeren hin, welches unerwärmt gelassen wird; ich fand dabei, dass die Kugeln gegen dieses Ende hin zusammengetrieben werden können und das Quecksilber also auf einem relativ beschränkten Raum zur Absetzung gebracht werden kann.

Sollte Unsicherheit darüber herrschen, wie es häufig besonders bei Bildung sehr kleiner Kugeln geschieht, ob das Vorliegende Quecksilberkugeln oder Luftblasen sind, so hat man nach W elander in der Erwärmung ein gutes Mittel für die Differentialdiagnose; die Luftblase bleibt auf ihrem Platz, wogegen die Quecksilberkugel verschwindet und an einer anderen Stelle der Röhre sublimirt.

Durch diese Methode können natïrlich keine absolut sicheren Quantitätsbestimmungen gemacht werden, da ja die approximative Schätzung der Grösse und Menge der Kugeln vollständig subjectiv ist. Gleichwohl habe auch ich gleich Welander diese quantitative Schätzung bei meinen Untersuchungen durchzuführen versucht und bin der Meinung, dass diese Abschätzung, da man nur den Vergleich zwischen den gemachten Analysen im Auge hat, vollständig ihren Platz ausfüllt, wenn nur beobachtet wird, dass stets dieselbe Urinmenge und dieselbe Vergrösserung zur Anwendung kommt und bei der Abschätzung Rücksicht auf das specifische Gewicht des Harnes genommen wird, denn bei niedrigem Gewicht kann nicht in demselben Verhältniss Quecksilber erwartet werden wie in Urin mit hohem specifischen Gewicht.

Welander hat seine Untersuchungen mit Hinsicht auf die Menge und Grösse der Kugeln in sechs Abtheilungen gruppirt. Ich habe nur 4 Gruppen aufgestellt und die von mir untersuchten Fälle in diese einzufïgen versucht und der.Uebersichtlichkeit wegen die Gruppen je nach der Quecksilbermenge mit 1, 2, 3 und 4 bezeichnet. So bezeichnet Nr. 1 wenig Quecksilberkugeln, wenn nur eine oder einige sehr kleine Kugeln sich vorfanden; Nr. 2 eine mittlere Menge Kugeln, d. h. ziemlich viel kleinere nder einige grössere, Nr. 3 viel Kugeln, wenn mehrere grosse oder sehr viele kleine Kügelchen sich fanden; sowie Nr. 4 sehr viel, wenn eine grosse Menge grosser und kleiner Kugeln nachgewiesen werden können. 
Es kann wohl bisweilen $Z$ weifel darüber entstehen, in welche der 4 Gruppen eine Ânalyse wirklich gehört; sind aber mehrere Analysen gemacht worden, so erleichtert die Gewohnheit eine approximative Bestimmung und die Analyse wird mit Leichtigkeit abgeschätzt, so dass sich keine wesentlichen Unrichtigkeiten einschleichen können.

Bei Ausführung der Analysen wurden alle denkbaren Vorsichtsmassregeln ergriffen, um mit Sicherheit Quecksilber aus anderen Quellen ausschliessen zu können. So wurde die grösste Sorgfalt der Reinigung aller Gefässe gewidmet, sowohl denen, in welchen der Urin erst aufgefangen wurde, wie allen Kolben, Decantirgläsern u. s. w., welche beim Kochen oder zur Aufbewahrung des Urins zur Anwendung kamen. Da auch die Salzsäure Quecksilber enthalten kann, so wurde sie stets vor der Anwendung untersucht. Ebenso können die vielen Analysen, welche vor Beginn der Behandlung an Patienten gemacht wurden, die früher keiner Quecksilberbehandlung unterworfen gewesen waren und die ein negatives Resultat ergaben, als Controlversuche dienen.

Šchliesslich mag erwähnt werden, dass sowohl Salicylquecksilber als auch Thymolquecksilberacetat in Mischungen von 0.1 auf 1.0 Paraffin in Dosen von 0.10 und 0.05 injicirt und dabei alle antiseptischen Vorsichtsmassregeln beobachtet wurden, um die Reaction möglichst einzuschränken. Das Paraffin wurde vor der Mischung gekocht, die Injectionsstelle desinficirt, ebenso die Spitze der Spritze durch Carbolsäure oder Erhitzen über einer Spiritusflamme. Die Injectionen wurden entweder in der Trochanterregion oder unter der Schulter gemacht. Dabei sind niemals Abseesse entstanden, aber bisweilen eine Infiltration um die Injectionsstelle, welche aber immer ron geringer Bedeutung war.

Dieselben Vorsichtsmassregeln wurden auch bei den wenigen Calomelinjectionen beobachtet; als Constituens für Calomel wurde Glycerin angewandt. Die Injectionen wurden subcutan, nicht in die Muskeln gemacht.

Zusammen sind 305 Untersuchungen über Quecksilber in Harne gemacht worden. Davon 237 nach Injection von $\mathrm{Hg}$. salicyl. oder Thym. acet. Hg., 8 nach Calomelinjectionen, 32 
Untersuchungen über d. Resorption u. Eliminat. des Quecksilb. 187

nach interner Behandlung, 19 nach Inunctions- und 9 nach gemischter Behandlung. Bei allen diesen Analysen habe ich ein Mikroskop von Verick angewandt mit Vergrösserung Objectiv Nr. 2. Ocul. 1.

Nr. 1.

H. 22 Jahre. Papulae mucosae faucium.

\begin{tabular}{|c|c|c|c|c|c|c|c|}
\hline 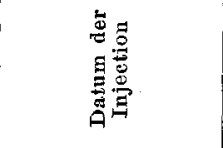 & 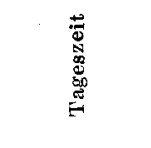 & 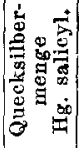 & 苛泀 & 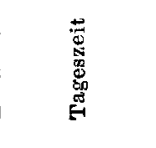 & 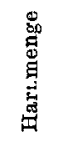 & 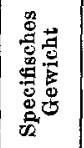 & 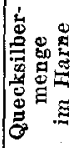 \\
\hline 14./XII.-15./IV. & - & 1,78 & $28 . / \mathrm{V}$ & 11 V.-M. & 300 & 1,025 & 1 \\
\hline- & - & - & $5 . / \mathrm{VI}$ & $7 \mathrm{~N} .-\mathrm{M}$. & 300 & 1,025 & 0 \\
\hline- & - & - & 6./VI. & $7 \mathrm{~V} .-\mathrm{M}$ & 300 & 1,015 & 0 \\
\hline $6 . / \mathrm{NI}$ & $1 / 411$ V.-M. & 0,10 & 7./VI. & $7 \%$ & 300 & 1,023 & 4 \\
\hline - & - & - & 7./VI. & $4^{1 / 2}$ N.-M. & 300 & 1,030 & 3 \\
\hline $9 . / \mathrm{VI}$. & 11 V.-M. & 0,10 & 10./VI. & 7 V.-M. & 300 & 1,023 & 4 \\
\hline 13./VI. & $11 \%$ & 0,10 & 19./VI. & $10^{1} / 2$ & 300 & 1,024 & 2 \\
\hline 19./VI. & 11 & 0,10 & $2 . / \mathrm{VIII}$ & $9 \%$ & 300 & 1,021 & 2 \\
\hline 25./VI. & 11 & 0,10 & - & 一 & - & 一 & - \\
\hline 2./VII. & 11 & 0,10 & 11./VII. & $11 \frac{1}{2}$ V.-M. & 300 & 1,010 & 3 \\
\hline - & 一 & 一 & 8./VIII. & $10 \%$ & 300 & 1,015 & 0 \\
\hline 一 & - & - & 25./VIII. & $11 n$ & 300 & 1,010 & 0 \\
\hline 一 & - & - & 8./IX. & $11 n$ & 300 & 1,011 & 0 \\
\hline - & - & - & 12./IX. & $11^{1} / 2$ & 300 & 1,020 & 0 \\
\hline
\end{tabular}

6 Wochen nach Beendigung der Injectionen, wobei im Laufe von 4 Monaten 1,78 Hg. salicyl. eingespritzt waren, enthielt der Urin eine geringe Menge Quecksilber, die eine Woche später verschwunden war; 18 und 30 . Stunden nach Injection von $0^{*} 10$ viel Quecksilber. 6, 10 und 14 Tage nach den Injectionen mittlere Menge Quecksilber. 6, 9, 91/2 Wochen, nachdem 0.60 im Laufe eines Monats injicirt worden, wurde kein Quecksilber mehr im Harne angetroffen. 
Nr. 2.

K. 22 Jahre. Papulae mucosae faucium. Laryngitis chr.

Pat. war 5 Wochen mit Quecksilber behandelt worden. Injection von $\mathrm{Hg}$. Salicyl. 0.50, darauf 1 Monat Schmiercur. 15 Päckchen, 2, 5, 9 Wochen später kein Quecksilber im Urine.

\begin{tabular}{|c|c|c|c|c|c|c|c|}
\hline 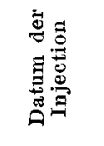 & 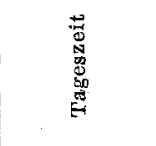 & 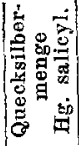 & 朂息 & 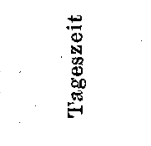 & 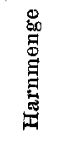 & 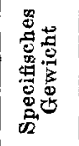 & $\mid \begin{array}{ll} & \\
0 \\
0 \\
0\end{array}$ \\
\hline $25 . / V$. & $12 \% / 2$ V.-M. & 0,10 & 25. V. & $4^{1} / 2$ N.-M. & 300 & 1,016 & 3 \\
\hline - & - & - & $26 . / \mathrm{V}$ & $7 \quad$ V.-M. & 300 & 1,023 & 2 \\
\hline $29 . / \nabla$. & $111 / 2$ V.-M. & 0,10 & $3 . / \mathrm{VI}$. & $10^{1} / 2 n$ & 300 & 1,021 & 0 \\
\hline 3./VI. & $11 \%$ & 0,10 & 13./VI. & $12^{1 / 2} \quad n$ & 300 & 1,016 & 3 \\
\hline 13./VI. & - & 0,10 & 19./VII. & 5 N.-M. & 250 & 1,013 & 0 \\
\hline - & - & - & $12 . / \mathrm{IX}$ & $41 / 2 \quad n$ & 300 & 1,028 & 0 \\
\hline
\end{tabular}

9 Wochen nach combinirter Quecksilberbehandlung kein Quecksilber im Urin. 4 und $18 \frac{1}{2}$ Stunden nach der Injection recht viel Quecksilber; 5 Tage nach der zweiten Injection keine Kügelchen? 10 Tage nach der 3. Einspritzung wieder Quecksilber. 7 Wochen und 3 Monate nach den letzten Einspritzungen keine Quecksilberkügelchen.

Nr. 3.

H. 24. Jahre. Syphilides papulosae. Adenopathia inguinalis.

\begin{tabular}{|c|c|c|c|c|c|c|c|}
\hline 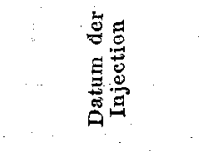 & 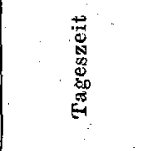 & 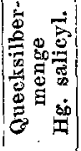 & 表蒫 & 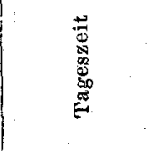 & 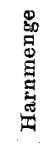 & 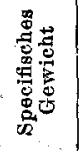 & 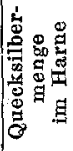 \\
\hline $1 . / \mathrm{II}-12 . / \mathrm{IV}$. & $\ldots$ & 0,80 & — & - & - & 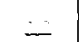 & $\ldots$ \\
\hline $29 . / \mathrm{IV}$ & - & 0,10 & $5 . / \mathrm{V}$. & - & - & - & 3 \\
\hline $5 . / V$. & V.-M. & 0,10 & 7./V. & 6 V.-M. & 130 & - & 3 \\
\hline - & & 一 & 17. V. & $31 / 2$ N.-M. & 300 & 1,026 & 2 \\
\hline 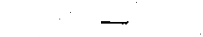 & & - & $19 . / \mathrm{V}$ & $10^{2}$ V.-M. & 300 & 1,023 & 2 \\
\hline $19 . \mathrm{V}$ & 11 V.-M. & 0,10 & 24./V. & $10 \% / 2$ & 300 & 1,005 & 0 \\
\hline $24 . / \mathrm{V}$. & 11 & 0,10 & - & - & - & - & - \\
\hline 18./VI. & $11 \frac{1}{2} \quad$ & 0,10 & 18./VI. & $12^{1} / 2$ N.-M. & 300 & 1,014 & 4 \\
\hline - & - & -- & 18./VI. & 9 & 300 & 1,020 & 4 \\
\hline - & $-\cdots$ & - & 19./VI. & $23 / 4 \quad "$ & 300 & 1,025 & 3 \\
\hline$\overline{20}_{\bar{N}}$ & $111 \mathrm{~V} M$ & -8 & 20./VI. & $9^{3} / 4$ & 300 & 1,029 & 3 \\
\hline 23. N1. & $11^{1 / 2}$ V.-M. & 0,10 & 23./VI. & $73 / 4$ & 300 & 1,022 & 3 \\
\hline 28. & $11 \frac{1}{2}$ & 0,10 & 29./VI. & 9 & 300 & 1,026 & 4 \\
\hline 9. VII. & 12 V.-M. & 0,10 & $\begin{array}{l}\text { 9./VII. } \\
\text { 11. VII. }\end{array}$ & $\begin{array}{c}11 \% / 2 \\
21 / 3\end{array}$ & $\begin{array}{l}300 \\
300\end{array}$ & 1,016 & 2 \\
\hline & & & & & & & \\
\hline
\end{tabular}


6 Tage nach Injection von $0.90 \mathrm{Hg}$. Salicyl. im Laufe von $2 \frac{1}{2} \mathrm{Mo-}$ naten fand sich eine grosse Menge Quecksilber im Urin. Nach den darauf gemachten 7 Injectionen fand sich 1,6,8 und 9 Stunden, sowie die nächsten Tage nach den Injectionen Quecksilber in grosser Menge, verminderte sich aber constant am 11-14. Tage nach der Injection. Nur in einer Analyse, 5 Tage nach der Injection, war der Harn quecksilberfrei; sein specifisches Gewicht betrug 1005.

11 Tage nach der Injectionscur wurde mit einer Schmiercur begonnen und fand sich dann wahrscheinlich noch Quecksilber im Harne vor.

\begin{tabular}{|c|c|c|c|c|c|c|}
\hline $\begin{array}{l}\dot{\Delta} \\
\dot{\Xi} \\
\dot{\Xi}\end{array}$ & 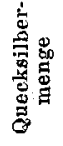 & 㤩莀 & 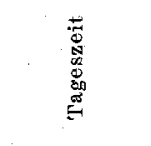 & 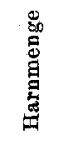 & 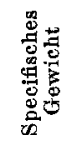 & 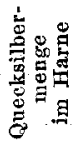 \\
\hline 7 & 2,5 & 20 /VII. & $11^{1} / \mathrm{V}-\mathrm{M}$ & 300 & 1.025 & 1 \\
\hline 30 & $\begin{array}{l}3,3 \\
2,5\end{array}$ & 12./VIII. & $3^{1 / 2}$ N.-M. & 300 & $\begin{array}{l}1,020 \\
1,024\end{array}$ & 3 \\
\hline 45 & 2,5 & 26./VIII. & & 300 & 1,010 & 1 \\
\hline 50 & 2,5 & 1./IX. & $41 \%$ & 300 & 1,017 & 1 \\
\hline - & - & $18 . / \mathrm{IX}$ & 11 V.-M. & 300 & 1,005 & 0 \\
\hline - & - & 24. IX. & $11^{3 / 4}$ & 300 & 1,021 & 4 \\
\hline - & - & 26./IX. & $12^{\prime 4}$ N.-M. & 300 & 1,014 & 1 \\
\hline
\end{tabular}

Die ganze Zeit während der Schmiercur Quecksilber im Urin. 18 Tage nach Abschluss der Cur kein Quecksilber im Harn, wahrscheinlich beruhend auf dem niedrigen spec. Gewicht; dagegen am 24. und 26. Tage wieder Quecksilber nachzuweisen.

Nr. 4.

S. 22 Jahre. Papulae mucosae faucium.

Patient 6 Monate früher mit Schmiercur behandelt, 73 Päckchen; ausserdem hat er damals Calomelinjectionen, 0.30 erhalten.

\begin{tabular}{|c|c|c|c|c|c|c|c|}
\hline 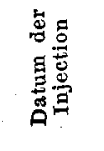 & 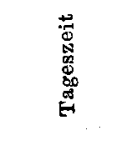 & 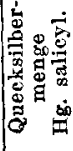 & 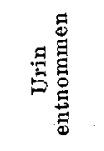 & 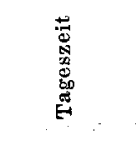 & 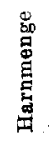 & 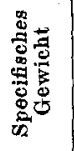 & 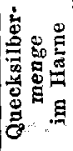 \\
\hline 29./IV. & 11 V.-M. & 0,10 & 29./V. & $5 \quad$ N. $-M$. & 300 & 1,025 & 1 \\
\hline - & 一 & & 16./VII & $81 / 2$ & 240 & 1,027 & 0 \\
\hline 20./IX. & - & - & 7./IX. & $21 / 2$ & 300 & 1,016 & 0 \\
\hline- & - & & 25./IX. & $1^{3} / 4$ V.-M. & 300 & 1,023 & 1 \\
\hline- & - & - & $7 . / \mathrm{X}$ & $11 / 2 \quad n$ & 275 & 1,020 & 1 \\
\hline 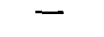 & - & - & 28./X. & 7 & 300 & 1,020 & 0 \\
\hline 一 & 一 & - & 5./XI. & $31 / 2$ N.-M. & 300 & 1,021 & 0 \\
\hline
\end{tabular}

Ungefähr 6 Stunden nach Injection von $0^{*} 10 \mathrm{Hg}$. salicyl. etwas Quecksilber im Harne. 5 Tage nach täglichem Gebrauch von Quecksilberpillen wenig Quecksilber. 4-5 Wochen nach Beendigung der Cur alles Quecksilber im Harn verschwunden. 
Nr. 5.

A. 21 Jahre. Ulcus induratum penis. Papulae mucosae scroti.

Patient hatte vor etwas mehr als $2 \frac{1}{2}$ Jahren Calomelinjectionen 0.30 erhalten.

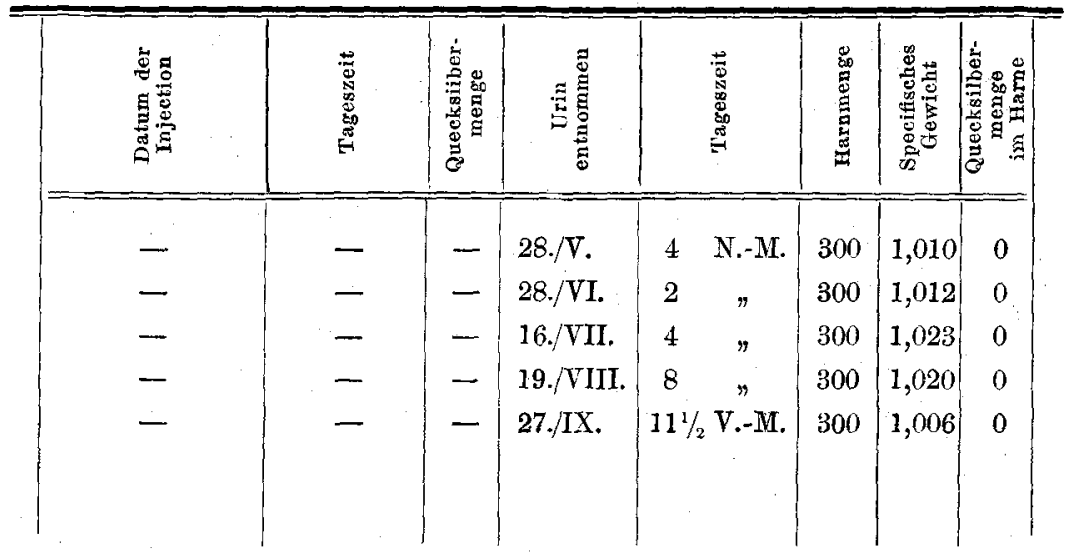

$2^{1 / 2}$ Jahre nach Calomelinjectionen kein Quecksilber im Urin. Der Harn wurde einmal monatlich während 5 Monate entnommen.

Nr. 6.

F. 19 Jahre. Ulcus induratum penis.

Vom 21. Sept. 1889 bis 15. Jänner 1890 erhalten Calomelinjectionen $0 \cdot 20$; Hg. salicyl. $0 \cdot 30$.

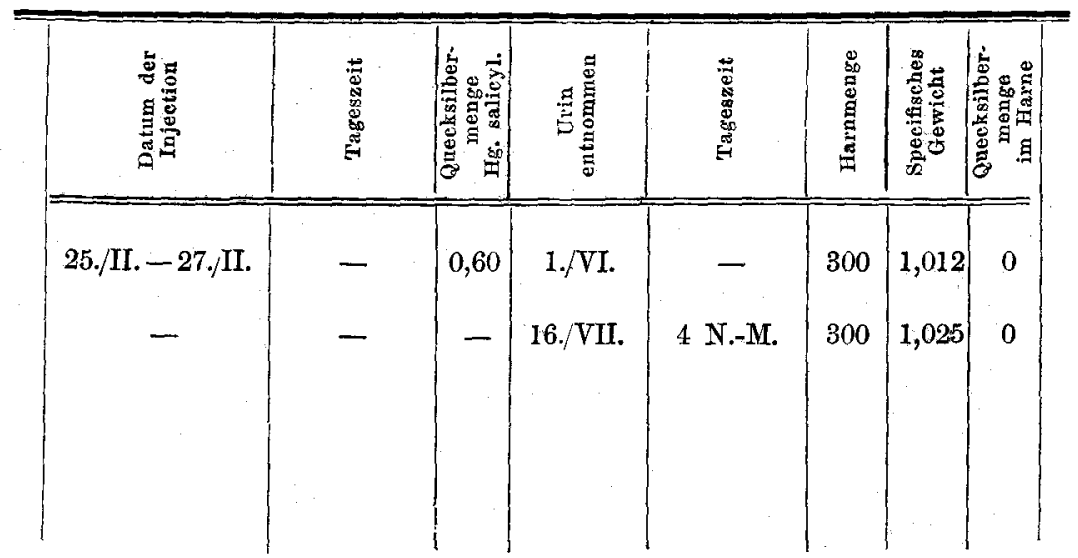

9-15 Wachen nach Beendigung einer vierwöchentlichen Injectionscur von $0.60 \mathrm{Hg}$. salicyl. kein Quecksilber im Urin. 
Nr. 7 .

L. Papulae mucosae faucium. Adoenopatia inguinalis.

Vom 4. März bis 24. April Hg. salicyl. 0.80 in Dosen von 0.10.

\begin{tabular}{|c|c|c|c|c|c|c|c|}
\hline 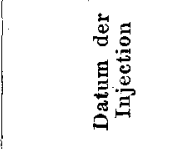 & 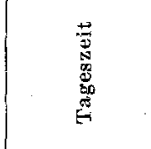 & 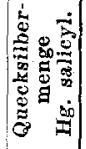 & 音苛 & 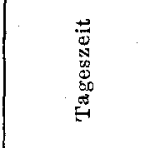 & 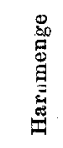 & 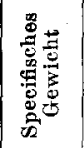 & 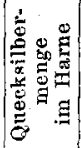 \\
\hline - & $\ldots$ & - & 17. V. & N.M. M. & 300 & - & 0 \\
\hline $17 . / \mathrm{V}$. & N.-M. & 0,10 & $18 / \mathrm{V}$ & 1 & 300 & - & 2 \\
\hline- & - & - & 19./V. & V.-M. & 300 & 1,015 & 2 \\
\hline & - & - & 21./V. & 10 & 300 & 1,017 & 3 \\
\hline $22 . / V$. & 11 V.-M. & 0,10 & $23 . / \mathrm{V}$ & 11 & 300 & 1,014 & 4 \\
\hline $26 . \mathrm{V} / \mathrm{.}$ & 10 & 0,10 & $27 . / \mathrm{V}$. & N.-M. & 300 & 1,016 & 4 \\
\hline 29./V. & & 0,10 & 2. VI. & V.-M. & 300 & 1,010 & 3 \\
\hline 2./VI. & $11 \frac{1}{2}$ V.-M. & 0,10 & 3./VI. & $1 / 2$ N.-M. & 300 & 1,011 & 4 \\
\hline $\bar{\pi}$ & & ( & 17./VI. & $9^{1 / 2}$ V.-M. & 300 & 1,023 & 1 \\
\hline 17./VI. & 11 V.-M. & 0,10 & - & $\mathrm{NT}$ & - & - & - \\
\hline $2 . \overline{I X}$ & $11 \%$ V.-M. & 0,10 & 31./VIII. & 3 N.-M. & $\begin{array}{r}300 \\
-\end{array}$ & 1,021 & 1 \\
\hline 6./IX. & $11^{1 / 4}$ & 0,10 & $\begin{array}{r}8 . / \mathrm{IX} . \\
25 . / \mathrm{IX} .\end{array}$ & $\begin{array}{ll}11^{1 / 2} & \text { V.-M. } \\
11 & \Rightarrow\end{array}$ & $\begin{array}{l}300 \\
300\end{array}$ & $\begin{array}{l}1,015 \\
1,006\end{array}$ & $\begin{array}{l}3 \\
1\end{array}$ \\
\hline
\end{tabular}

$3 \frac{1}{2}$ Wochen nach der Injectionscur kein Quecksilber. 18 Stunden wach Inject. von $0 \cdot 10 \mathrm{Hg}$. salicyl. recht viel Quecksilber, das am 3. Tage zunahm und sich nach den späteren Injectionen, die mit Pausen von einigen Tagen stattfanden, stark vermehrte, aber 2 Wochen nach der letzten Injection stark abnahm. Nach interner Behandlung und Schmiercur etwas Quecksilber, das sich nach 2 Injectionen vermehrte, aber 19 Tage später stark abnahm.

Nr. 8.

J. 20 Jahre. Ulcera syphilitica faucium.

Vom 10. Jänner bis 28. Febr. 1889 Calomel 0.20, 26. Oct. 1889 020. 30. Oct. bis 8 . Nov. 1889 Jod.-K. + Deutojod. hydrarg.

\begin{tabular}{|c|c|c|c|c|c|c|c|}
\hline 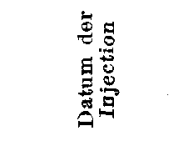 & 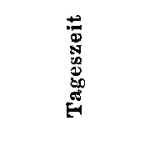 & 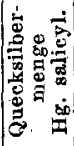 & 焉䍖 & 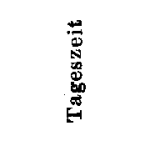 & 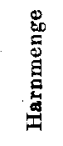 & 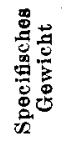 & 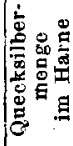 \\
\hline$\frac{-}{-} \underset{\text { 3./X. } 1890 .}{\text { 21./X. }}$ & $\begin{array}{l}\frac{\bar{Z}}{11 \overline{\mathrm{V}} \cdot-\mathrm{M} .} \\
111 / 4 \quad n\end{array}$ & $\begin{array}{l}- \\
\overline{-} \\
0,10 \\
0,05\end{array}$ & $\begin{array}{l}28 . / \mathrm{V} .90 \\
5 . / \mathrm{VI} . \\
1 . / \mathrm{X} . \\
3 . / \mathrm{X} . \\
22 / . \mathrm{X} .\end{array}$ & $\begin{array}{l}11 \frac{1 / 2}{} \text { V.-M. } \\
11 \frac{1}{2} \text { " } \\
81 / 2 \\
3 \quad \text { N.-M. } \\
7 \quad \text { V.-M. }\end{array}$ & $\begin{array}{l}300 \\
300 \\
300 \\
300 \\
200\end{array}$ & $\begin{array}{l}1,029 \\
1,024 \\
1,013 \\
1,018 \\
1,018\end{array}$ & $\begin{array}{l}0 \\
0 \\
0 \\
3 \\
4\end{array}$ \\
\hline
\end{tabular}

$6 \frac{1}{2}$ und $10^{1 / 2}$ Monate nach Calomelinjectionen und interner Quecksilberbehandlung dieses aus dem Urin verschwunden. 4 Stunden nach der ersten Injection recht viel Quecksilber, das sich nach einer folgenden Injection vermehrte. 
Nr. 9 .

A. 23 Jahre. Ulcus induratum penis. Syphilis maculopapulosa. Adaenopat. inguinal.

\begin{tabular}{|c|c|c|c|c|c|c|c|}
\hline 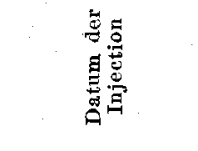 & 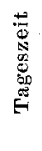 & 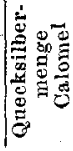 & 离泀 & 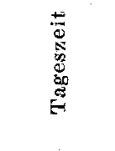 & 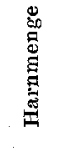 & 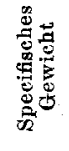 & 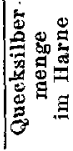 \\
\hline $11 . \mathrm{XII}_{1889}-7 . / \mathrm{I}$ & - & 0,25 & $\begin{array}{l}3 . / \mathrm{VI} \text {. } \\
1890\end{array}$ & 6 N.-M. & 300 & 1,020 & 0 \\
\hline
\end{tabular}

17 Monate nach Beendigung der Cur kein Quecksilber im Harne.

Nr. 10.

R. 23 Jahre. Syphilis maculo-papulosa. Angina syphilitica.

\begin{tabular}{|c|c|c|c|c|c|c|c|}
\hline 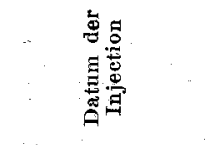 & 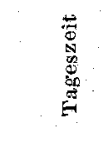 & 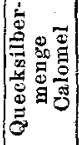 & 急泀 & 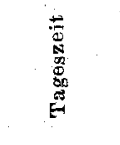 & 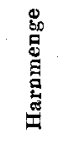 & 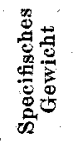 & 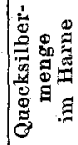 \\
\hline $20 . /{ }_{1888}-7 . /$ III. & - & 0,20 & $\begin{array}{l}7 . / \mathrm{VI} . \\
1890\end{array}$ & $6 \mathrm{~N} \cdot \mathrm{M}$. & 300 & $1 ; 011$ & 0 \\
\hline
\end{tabular}

26 Monate nach der letzten Injection kein Quecksilber im Harne.

Nr. 11.

U. 24 Jahre. Ulcus induratum penis.

\begin{tabular}{|c|c|c|c|c|c|c|c|}
\hline 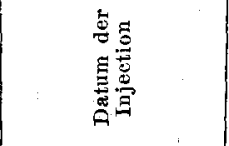 & 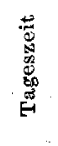 & 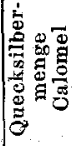 & 芯蓄 & 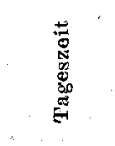 & 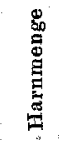 & 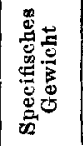 & 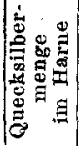 \\
\hline $\begin{array}{c}10 . / \mathrm{IX} .-25 . / \mathrm{IX} \\
1889 .\end{array}$ & - & 0,20 & $\begin{array}{l}7 . / \mathrm{VI} \\
1890\end{array}$ & $7 \mathrm{~N}-\mathrm{M}$ & 200 & 1,023 & 0 \\
\hline
\end{tabular}

8 Monate nach der letzten Injection kein Quecksilber im Harne.

Nr. 12.

A. 23 Jahre. Ulcus induratum penis. Roseola syphilitica. Papulae mucosae faucium.

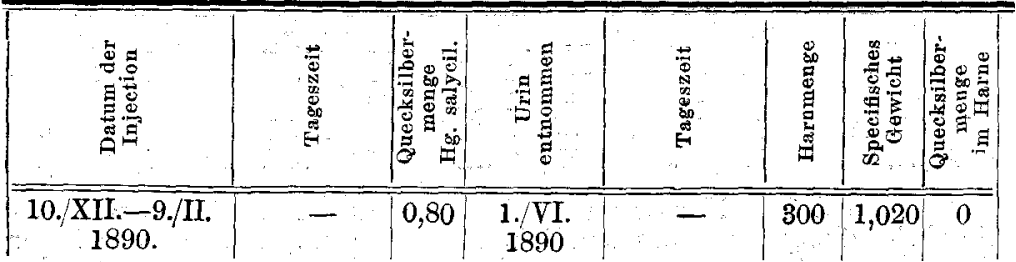

Nahezu 31/2 Monate nach Schluss der Behandlung keine Kügelchen. 
Nr. 13.

S. 29 Jahre. Orchitis syphilitica. Syphilis gummosa.

\begin{tabular}{|c|c|c|c|c|c|c|c|}
\hline 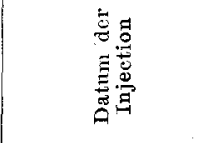 & 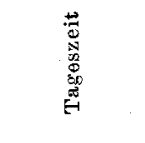 & 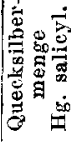 & 苋 & 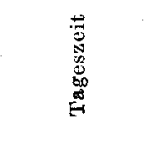 & 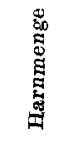 & 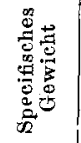 & 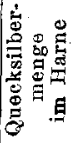 \\
\hline $14 . / \mathrm{IV} .-19 . / \mathrm{IV} .90$ & - & 0,15 & $4 . / \mathrm{VI}$. & $12^{1 / 2}$ N.-M. & 300 & 1,022 & 0 \\
\hline$-1-$ & - & - & 29./VIII. & 1 & 300 & 1,012 & 0 \\
\hline 30./VIII. & $11^{1 / 2}$ V.-M. & 0,10 & 30./VIII. & 6 & 300 & 1,031 & 3 \\
\hline- & - & - & 31./VIII. & V.-M. & 300 & 1,021 & 3 \\
\hline- & - & - & 31./VIII. & $9^{-1 / 2}$ N.-M. & 300 & 1,020 & 2 \\
\hline- & 一 & - & $3 . / \mathrm{IX}$. & 6 & 300 & 1,028 & 1 \\
\hline 4./IX. & $111 / 2$ V.-MI. & 0,10 & 4./IX. & $31 / 2$ & 300 & 1,021 & 4 \\
\hline 9. IX. & 11 & 0,10 & 10./IX. & 1 & 300 & 1,021 & 4 \\
\hline 16./IX. & - & 0,10 & 25./IX. & $3^{1 / 2}$ & 300 & 1,010 & 4 \\
\hline- & - & - & 6./X. & & 300 & 1,011 & 0 \\
\hline - & - & 一 & $16 . / \mathrm{X}$ & 11 V.-M. & 300 & 1,014 & 2 \\
\hline - & - & - & 4./XI. & $11 \frac{1}{2} \quad "$ & 300 & 1,013 & 3 \\
\hline
\end{tabular}

6 Wochen und $4 \frac{1}{2}$ Monate nachdem $0.15 \mathrm{Hg}$. salicyl. innerhalb 5 Tagen injicirt worden, kein Quecksilber: $6 \frac{1}{2}$ Stunden nach Injection von 0.10 grosse Menge Quecksilber, die sich den folgenden Tag unverändert erhielt, aber 4 Tage später abnahm, um nach den folgenden, mit ungefähr einwöchentlichen Pausen gemachten Injectionen wieder stark zu steigen. 4 und 7 Wochen hierauf war noch Quecksilber vorhanden, verschwand aber 3 Wochen nach der letzten Injection.

Nr. 14.

H. 22 Jahre. Syphilis maculosa. Papulae mucosae faucium. Schmiercur mit Ung. Hg. 1·50, 5 Päckchen. 25. Oct. 1889.

\begin{tabular}{|c|c|c|c|c|c|c|c|}
\hline 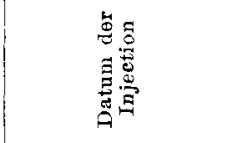 & 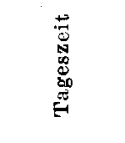 & 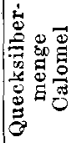 & 焉泀 & 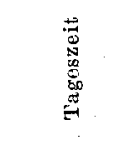 & 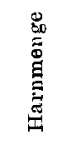 & 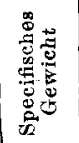 & 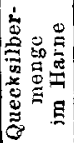 \\
\hline 1. XI.-2. XII 89 & $=$ & 0,30 & $29 . / \mathrm{V} .90$ & $7 \overline{\mathrm{V}} \cdot \mathrm{-M}$. & 300 & 1,017 & 0 \\
\hline- & - & $\frac{-}{\mathrm{Hg} \cdot \mathrm{s} .}$ & 11. $\mathrm{X}$. & $3 \frac{1}{2} \mathrm{~N}-\mathrm{M}$. & 300 & 1,014 & 0 \\
\hline $26 . / \mathrm{X}$ & 10 V.-M. & 0,10 & $26 . / \mathrm{X}$. & 8 & 300 & 1,017 & 4 \\
\hline- & - & & 27. $\mathrm{X}$. & & 300 & 1,030 & 1 \\
\hline 1./ XI. & - & 0,10 & 6./XI. & $8^{1} / 2 .-\mathrm{M}$. & 300 & 1,015 & 2 \\
\hline 7./XI. & - & 0,10 & 25./XI. & 6 N.-M. & 175 & 1,018 & 0 \\
\hline- & - & - & 27./XI. & $8 \%$ V.-M. & 300 & 1,022 & 1 \\
\hline - & - & - & 14./XII. & $n$ & 300 & 1,017 & 0 \\
\hline
\end{tabular}

6 und $10 \%$ Monate, nachdem im Laufe von 5 Wochen Einreibung von 7.50 grauer Salbe und Injection von Calomel 0.30 angewandt wai, kein Quecksilber im Harne. 10 Stunden nach Injection von Hg. salicyl. 010 viel Quecksilber, das schon am nächsten Tage bedeutend vermindert war. 5 Tage nach der zweiten Injection von 0.10 wieder stark vermeht'. 20 Tage nach der 3. Einspritzung noch unbedeutend Quecksilber, verschwand ganz nach 5 Wochen. Dass am 18. l'age nach der 3. Inj. kein Quecks. zu finden war, beruhte wahrscheinlich auf der geringen Urinmenge. 
Nr. 15.

W. Ulcus induratum penis. Roseola syphilitica. Papulae mucosae faucium. Adenopatia inguinalis.

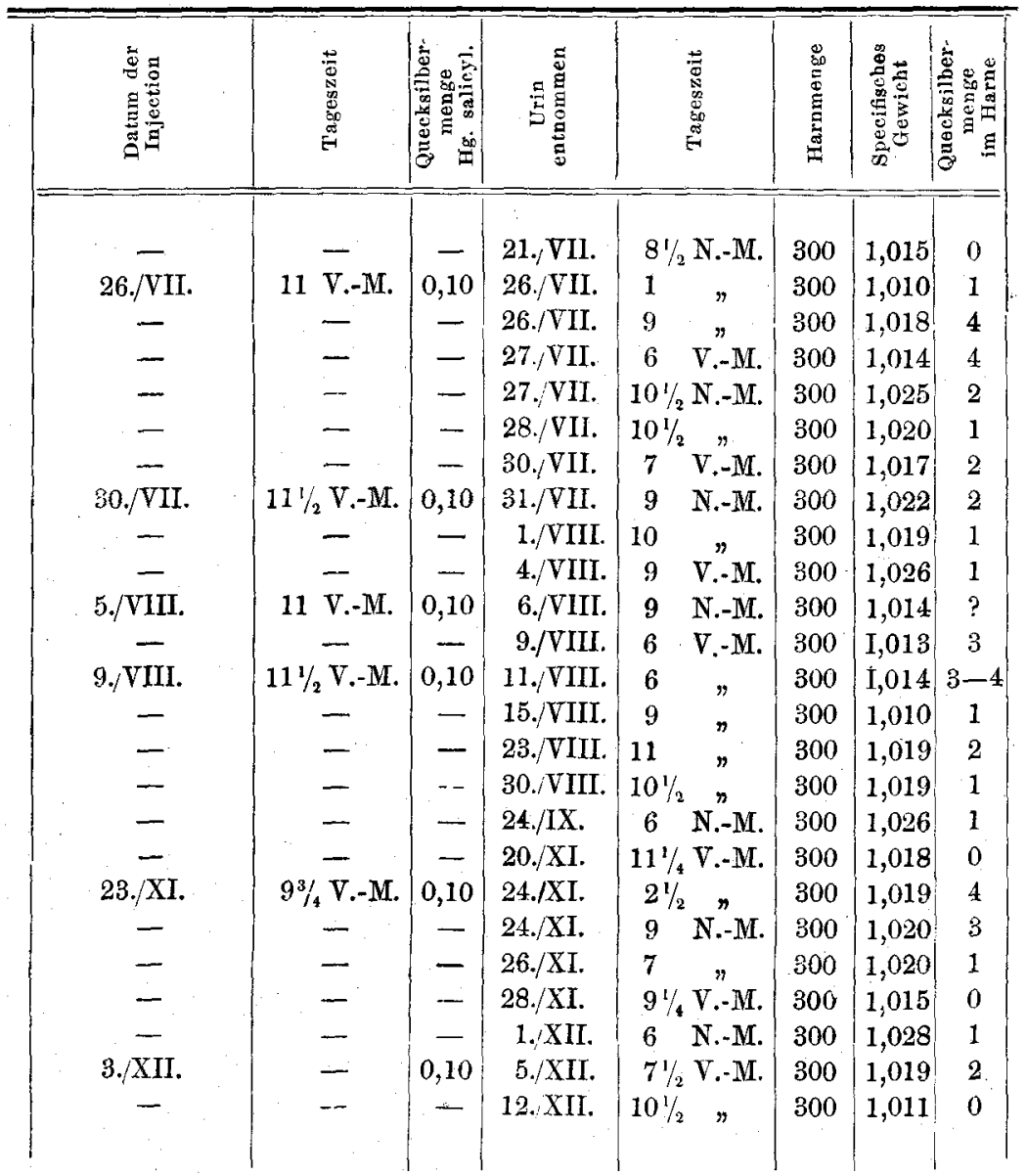

2 Stunden nach Injection von 0.10 geringe Menge Quecksilber; nach 1) Stunden grosse Menge, die schon in der zweiten Hälfte des folgenden Tages und die nächsten 4 Tage abnimmt, um wieder 10 Stunden nach der uächsten Injection zuzunehmen und sich in den nächsteu Tagen wieder zu vermindern; während dreier Wochen nach der 4. Injection schwankende Quantität, nach $6^{1 / 2}$ Wochen nur geringe Menge. 15 Wochen nach der 4. In Jection von 0.10 kein Quecksilber. 16 Stunden nach erneuerter Inject. von $0 \cdot 10$ in der Urinprobe viel Quecksilber, das während der nächsten T'age abnimmt und 5 Tage darauf verschwanden ist. Nach einigen Tagen wieder nachweisbar. Nach der letzten Injection von $0^{*} 10$ wieder Quecksilber, das 9 Tage später versebwunden ist. 
Nr. 16.

L. Roseola syphilitica. Papulae mucosae faucium. Adoenopatia inguinalis et cervicalis.

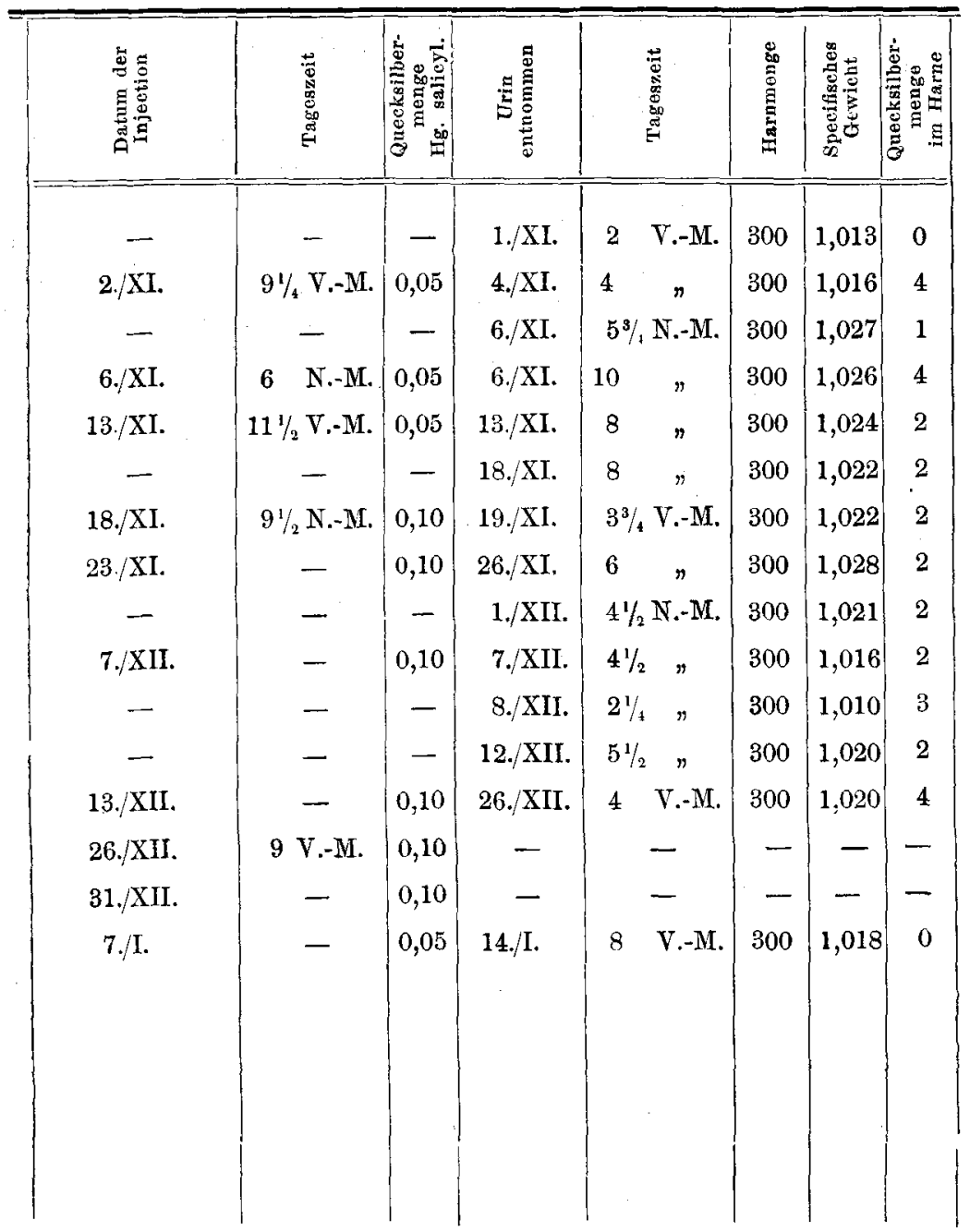

2 Tage nach Injection von 0.05 viel Quecksilber, das am 4. Tage abgenommen hat. 4 Stunden nach der nächsten Inject. von 0.05 starke Vermehrung. Nach Inject. von 0.05 und $0 \cdot 10$, die mit Pausen von einigen Tagen unternommen wurden, recht reichlich Quecksilber. 7 Tage nach der letzten Injection von 0.05 kein Quecksilber. 
Nr. 17.

T. 22 Jahre. Papulae mucosae ani.

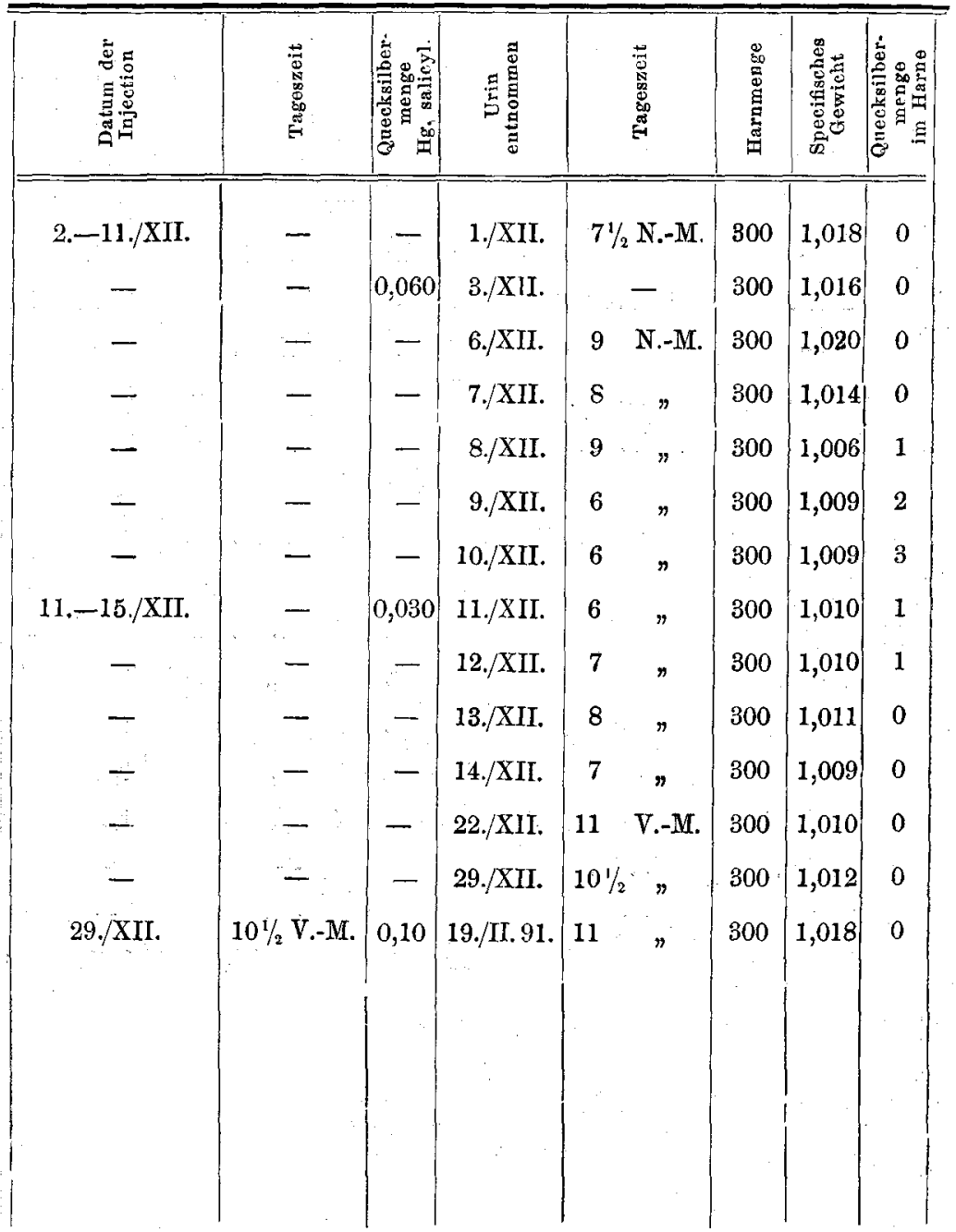

Nach interner Behandlung mit $\mathrm{Hg}$. salicyl. 0.060 täglich, waren am 6. Tage Spuren von Quecksilber zu entdecken, das am 9. Tage etwas zunahm und wieder verschwand. Da am 5. Tage nur 0.030 eingenommen wurde, konnte 14 Tage nach Aufhören der internen Behandlung kein Quecksilber nachgewiesen werden. 7 Wochen nach einer Injection von 0.10 Hg. salicyl. kein Quecksilber. 
Nr. 18.

W. 31 Jahre. Iritis syphilitica.

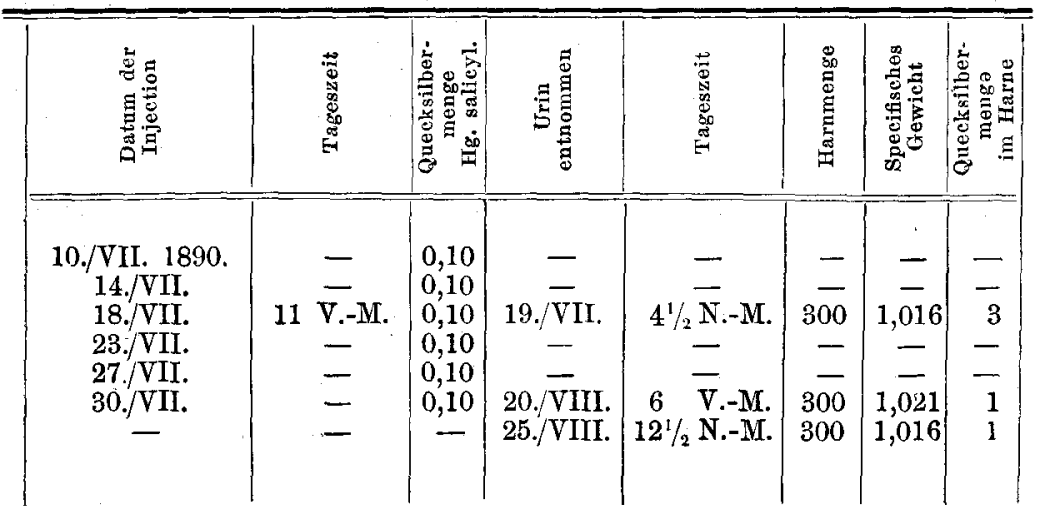

29 Stunden nach Injection von 0.30 innerhalb 8 Tagen, recht viel Quecksilber. Nach Injection von 0.60 innerhalb 3 Wochen wenig Quecksilber, das 8 Wochen nach der letzten Iajection ganz verschwunden ist.

Nr. 19.

K. 22 Jahre. Ulcus induratum penis. Sypbilides maculopapulosae. Papulae mucosae faucium.

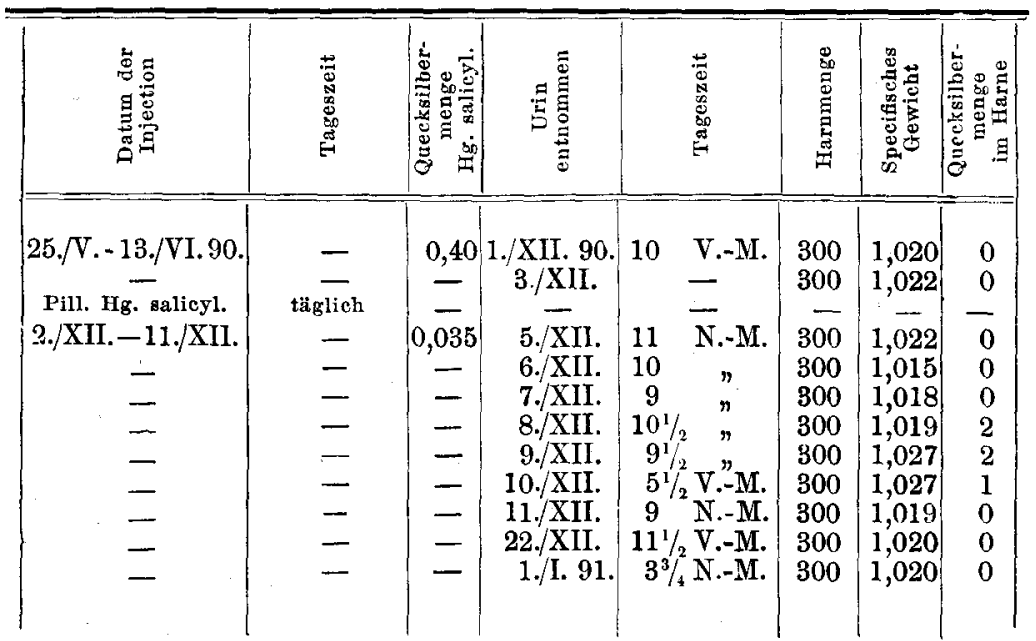

$5 \frac{1}{2}$ Monate nach Inject. von $0.40 \mathrm{Hg}$. salicyl. kein Quecksilber im Urine. Nach Einnahme von $0.035 \mathrm{Hg}$. salicyl. in Pillen täglich tritt das Quecksiber im Mittel erst am 6. Tage im Urine auf; am 11, und 20. Tage nach der Einnahme war kein Quecksilber mehr zu finden. 
Ö. 30 Jahre. Ulcus induratum penis. Adaenopatia inguinalis. Roseola syphilitica.

\begin{tabular}{|c|c|c|c|c|c|c|c|}
\hline 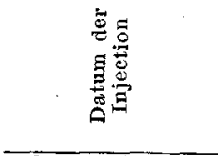 & 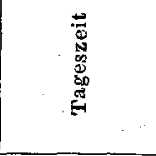 & $\mid \begin{array}{ll}0 & \\
3 \\
3\end{array}$ & 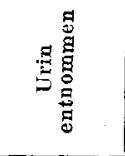 & 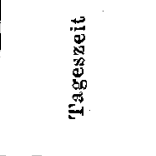 & 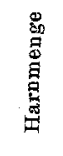 & 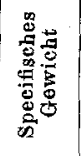 & 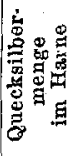 \\
\hline 3./X. - 7./X. 90 & - & 一 & 7./X. 90. & 7 N.-M. & 300 & 1,013 & 0 \\
\hline - & - & - & $11 . / \mathrm{X}$ & $9 \quad$ & 300 & 1,012 & 0 \\
\hline 15. $/ \mathrm{X}$. & $111 / 4$ V.-M. & 0,05 & 15. $/ \mathrm{X}$. & $31 / 2$, & 300 & 1,017 & 1 \\
\hline - & 一 & - & $17 . / \mathrm{X}$ & $10^{1} / 2$ & 300 & 1,019 & 2 \\
\hline $20 . / \mathrm{X}$ & $11 \quad \mathrm{~V} . \mathrm{M}$. & 0,05 & $20 . / X$ & $6 \%$ & 300 & 1,025 & 3 \\
\hline 23. $/ \mathrm{X}$. & - & 0,05 & -- & - & - & - & - \\
\hline 27./X. & $11^{1 / 2}$ V. - M. & 0,05 & $28 . / X$ & $5 \quad \mathrm{~V},-\mathrm{M}$. & 300 & 1,019 & 4 \\
\hline - & 一 & 一 & $10 . / \mathrm{XI}$ & $10 \%$ & 300 & 1,026 & 2 \\
\hline 10./XI. & 10\% V.-M. & 0,05 & - & $一$ & - & - & - \\
\hline 18./XI. & $10^{3 / 4}$ & 0,10 & $25 . / \mathrm{XI}$ & $10 \frac{1}{2}$ V.-M. & 300 & 1,017 & 3 \\
\hline $25 . / \mathrm{XT}$. & $10^{3} / 4$ & 0,10 & 2./XII. & $10^{1} / 2$ & 300 & 1,023 & 0 \\
\hline 2./XII. & $10^{1} / 2 \quad "$ & 0,10 & - & - & - & - & - \\
\hline $15 . / \mathrm{XII}$ & 一 & 0,10 & - & - & - & - & 一 \\
\hline 29./XII. & 一 & 0,10 & - & 一 & - & - & 一 \\
\hline 17./I. 91. & - & 0,10 & 2./II. & $10^{1} / 2$ V.-M. & 300 & 1,018 & 2 \\
\hline 2./II. & $10^{3} / 4$ V.-M. & 0,05 & 10./II. & 8 & 300 & 1,018 & 0 \\
\hline 10./II. & $10^{3 / 4}$ & 0,05 & $17 . / \mathrm{II}$ & $101 / 2 \ldots$ & 300 & 1,017 & 2 \\
\hline 17./I. & $10^{3} / 4 \quad n$ & 0,05 & 13./III. & 8 & 300 & 1,015 & 1 \\
\hline - & - & - & 26./III. & 8 & 300 & 1,028 & 0 \\
\hline
\end{tabular}

Am letzten Tage eines 5tägigen innerlichen Gebrauchs von Quecksilber und 4 Tage später kein Quecksilber im Harne. Ung. $4^{1 / 2}$ Stunden nach Inject. von 0.05 wenig Quecksilber, 2 Tage später etwas vermehrt. Nach der darauf folgenden Inject. von 0.05 starke Vermehrung; innerhalb 7-15 Stunden später recht viel Quecksilber. 16 Tage, nachdem 0.85 in drei Monaten injicirt waren, grosse Menge Quecksilber. Nahezu 4 Wochen nach 3 Inject. von 0.05 innerhalb 15 Tagen, fndet sich eine geringe Menge Quecksilber, die 5 Wochen später verschwunden war. 
$\mathbf{N r} \cdot 21$.

B. 21 Jahre. Adaenopatia inguinalis. Papulae mucosae faucium. Hatte während des Juni eine Calomelinjection erhalten und 14 Päckchen mit 2.5 Ung. Hg.

\begin{tabular}{|c|c|c|c|c|c|c|c|}
\hline 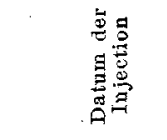 & 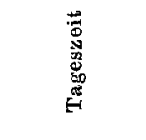 & 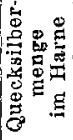 & 馜葛 & 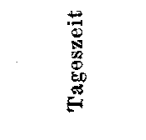 & 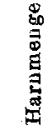 & 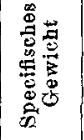 & 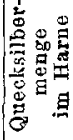 \\
\hline - & - & - & 9./IX. & $6^{1 / 2}$ V.-M. & 300 & 1,017 & 0 \\
\hline - & 一 & 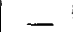 & 12. IX. & $5^{3 / 4}$ & 300 & 1,020 & 0 \\
\hline 17./IX. & $11^{3 / 4} \nabla .-M$. & 0,05 & 17./IX. & 8 N.-M. & 300 & 1,016 & 4 \\
\hline - & - & - & 18./IX. & $\dot{2}^{1} / 2$ V.-M. & 300 & 1,017 & 2 \\
\hline - & - & - & 18./IX. & $91 / 2$ N.-M. & 300 & 1,015 & 4 \\
\hline - & 一 & - & 19./IX. & 7 & 300 & 1,017 & 3 \\
\hline - & - & - & 21./IX. & & 150 & 1,020 & $I$ \\
\hline - & - & 一 & 23./IX. & $6^{3 / 4}, n$ & 300 & 1,026 & 2 \\
\hline 一 & & & $6 . / \mathrm{X}$ & $6^{1 / 2}$ N.-M. & 300 & 1,016 & 2 \\
\hline- & 一 & - & 17. $/ \mathrm{X}$ & $5 / 2$ V.-M. & 300 & 1,025 & 0 \\
\hline 19./XI. & 一 & 0,05 & 27./XI. & $7 \%$ & 300 & 1,019 & 0 \\
\hline 3./XII. & & 0,10 & 15. XII. & $6^{1 / 2}$ N.M. & 300 & 1,020 & 0 \\
\hline- & & - & 31./XII. & $11^{1 / 2}$ V.-M. & 300 & 1,021 & 0 \\
\hline 31./XII. & $11^{1} / 2$, V.-M. & 0,10 & 14./I. & $6 \%$ & 300 & 1,020 & 0 \\
\hline 14./I. & $10 \%$ & 0,10 & 2./II. & 11 & 300 & $1,020 \mid$ & 0 \\
\hline $2 . / \mathrm{II}$. & $11^{1 / 4}$ & 0,05 & 10./11. & $10^{1} / 2$ & 300 & 1,020 & 0 \\
\hline 10./II. & $10^{3} / t$ & 0,05 & 17./II. & $10 \%$ & 300 & 1,021 & 1 \\
\hline 17./II. & $10^{3 / 4}$ & 0,05 & 13./III. & $10^{1 / 2}$ & 300 & 1,018 & 3 \\
\hline- & & & 26./III. & $10^{1 / 2}$ & 300 & $\mid 1,015$ & 0 \\
\hline
\end{tabular}

Ungefähr 10 Wochen nach einer Calomelinjection und Inunctionscur (14 Päckchen) während 1 Monats, fand sich kein Quecksilber im Harne. 8 Stunden nach Inject. von 0.05 viel Quecksilber, das sich bei wiederholten Untersuchungen noch 19 Tage darauf in ziemlicher Menge vorfand. Nur eine Analyse ergab eine geringe Menge, aber da wurde die Untersuchung an nur 150 Gramm Urin gemacht. Bei wiederholten Untersuchungen 8, $12,14,19$ und 30 Tage nach Inject. von $0 \cdot 10-0 \cdot 05$ fand sich kein Quecksilber. Es trat wieder am 7. und 24. Tage nach 2 Inject. von 0.05 auf und verschwand wach 5 Wochen.

Nr. 22.

S. 28 Jahre. Papulae mucosae faucium, scroti et ani.

\begin{tabular}{|c|c|c|c|c|c|c|c|}
\hline 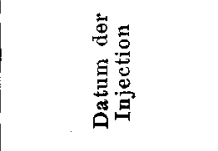 & 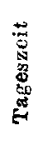 & 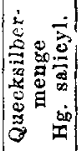 & 点莺 & 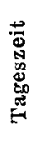 & 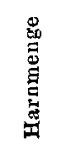 & 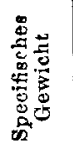 & 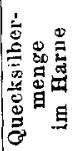 \\
\hline 3./VIII $-13 / \mathrm{IX}$ & - & 0,50 & 13. $\mathrm{X}$ & - & 300 & 1,023 & 2 \\
\hline- & - & , & $22 . / X$ & - & 300 & 1,020 & 0 \\
\hline 22./X. & - & 0,10 & 1. XI. & - & 300 & 1,025 & 2 \\
\hline - & - & - & 10./XI. & - & 300 & 1,016 & $\theta_{1}$ \\
\hline
\end{tabular}

Noch 4 Woohen nach 6wöchentlicher Behandlung mit $0.50 \mathrm{Hg}$. salicyl. enthielt der Urin Quecksilber das 9 Tage später verschwunden ist. Nach Inject. von $0 \cdot 10$, anderthalb Wochen später, enthält der Urin recht viel Quecksilber, das 19 Tage darauf verschwunden ist. 
Nx. 23.

B. 21 Jahre. Lichen syphiliticus. Adaenopatia inguinalis cubitalis et cervicalis. Papulae mucosae faucium. Syphilis

gummosae.

Vom 10. Jänner bis 21. April mit Hg. salicyl. 1.15 und Calomel $0 \cdot 10$ behandelt.

\begin{tabular}{|c|c|c|c|c|c|c|c|}
\hline 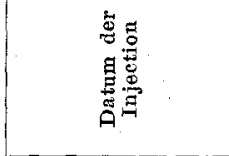 & 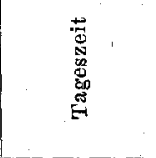 & 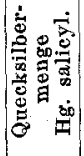 & 急 & 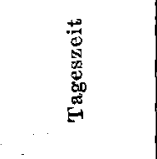 & 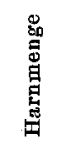 & 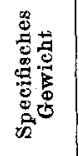 & 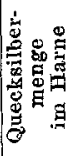 \\
\hline 8./V. & 12 V.-M. & 0,10 & - & - & - & - & - \\
\hline $9 . / \mathrm{V}$. & 11 V.-M. & 0,10 & - & - & - & - & - \\
\hline $15 . / V$ & 11 V.-M. & 0,10 & 16./V. & 11 V.-M. & 300 & 1,025 & 4 \\
\hline- & - & - & 19./V. & $10^{1} / 2$ & 300 & 1,017 & 1 \\
\hline 19./V. & $12^{1} / 2$ V.-M. & 0,10 & $24 . / V$. & 10 & 300 & 1,010 & 3 \\
\hline $24 . / \mathrm{V}$. & $11 \mathrm{~V} .-\mathrm{M}$. & 0,10 & 3./VI. & 10 & 300 & 1,012 & 2 \\
\hline $3 . / V I$. & $111 / 4$ V.-M. & 0,10 & $20 . / \mathrm{VI}$ & $10 \% / 2$ & 300 & 1,005 & 2 \\
\hline 20./VI. & $10^{3} / 4$ V.-M. & 0,10 & 23./VI. & $101 / 2 n$ & 300 & 1,008 & 4 \\
\hline 23./VI. & $11 \frac{1}{2}$ V.-M. & 0,10 & 28./VI. & $10^{1 / 2}$ & 300 & 1,005 & 3 \\
\hline 28./VI. & $11^{1 / 4}$ V.-M. & 0,10 & 5./ VII. & $10^{1 / 2}, n$ & 300 & 1,015 & 2 \\
\hline $5 . /$ VII. & 11 V.-M. & 0,10 & 14/VII. & 8 & 300 & 1,020 & 2 \\
\hline - & - & - & 19./VII. & $10^{1 / 2} "$ & 300 & 1,013 & 2 \\
\hline 19./VII. & $11 \mathrm{~V} .-\mathrm{M}$ & 0,10 & 13./VIII. & $10^{1 / 2}$ & 300 & 1,012 & 0 \\
\hline- & - & - & 15./IX. & $4 \quad$ N.-M. & 300 & 1,018 & 0 \\
\hline - & - & 一 & 3. $\mathrm{X}$. & 71/2 V.-M. & 300 & 1,023 & 0 \\
\hline 12./X. & 9 V.-M. & 0,10 & 12./X. & $11 \quad$ & 300 & 1,016 & 1 \\
\hline- & - & - & $21 . / X$ & $61 / 2$ N.-M. & 300 & 1,027 & 3 \\
\hline - & - & - & $26 . / \mathrm{X}$ & $8 \frac{1}{2}$ V.-M. & 300 & 1,023 & 0 \\
\hline- & - & - & 5./XI. & 7 & 300 & 1,017 & 0 \\
\hline- & 一 & - & 19./XI. & $91 / 2$ & 300 & 1,020 & 1 \\
\hline- & - & - & 28./XI. & 8 & 300 & 1,020 & 0 \\
\hline 11./XII. - 23./XII. & $\begin{array}{l}\text { Inunction } \\
\mathrm{N}_{\mathrm{r}} \mathrm{X} .\end{array}$ & 2,0 & 19./XII. & 9 & 300 & 1,021 & 0 \\
\hline- & + & - & 6./I. & $91 / 2 \quad "$ & 300 & 1,024 & 1 \\
\hline 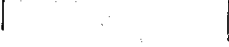 & & & & & & & \\
\hline
\end{tabular}

Im Laufe von 41/2 Monaten war 0.10 Calomel und 1.15 Hg. salicyl. injicirt worden. Einen Tag nach der letzten Injection von $0 \cdot 10$ viel Quecksilber; nach wiederholten Injectionen von $0 \cdot 10$ constant Quecksilber bis zum 14. und 17. Tage. Nach Pausen] von $3 \frac{1}{2}, 8$ und 10 Wochen kein Quecksilber. 2 Stunden nach Injection von 0.10 wieder etwas Quecksilber, das sich 9 Tage später vermehrt hat, aber nach dem 14. Tage so gut wie verschwunden war. Drei spätere Untersuchungen gaben unsichere und negative Resultate. 8 Tage nach Beginn einer Schmiercur kein Quecksilber, 14 Tage nach Einreibung von 10 Päckchen geringe Menge Kugelchen. 
Untersuchungen über d. Resorption u. Eliminat. des Quecksilb. 201 $\mathrm{Nr}, 24$.

F. 23 Jahre. Ulcus induratum penis. Papulae mucosae faucium et labii et Adaenopatia inguinalis. erhalten.

Hat vom 22. Nov. bis 18. Dec. 0.30 Hg. sal. in Dosen von 0.05

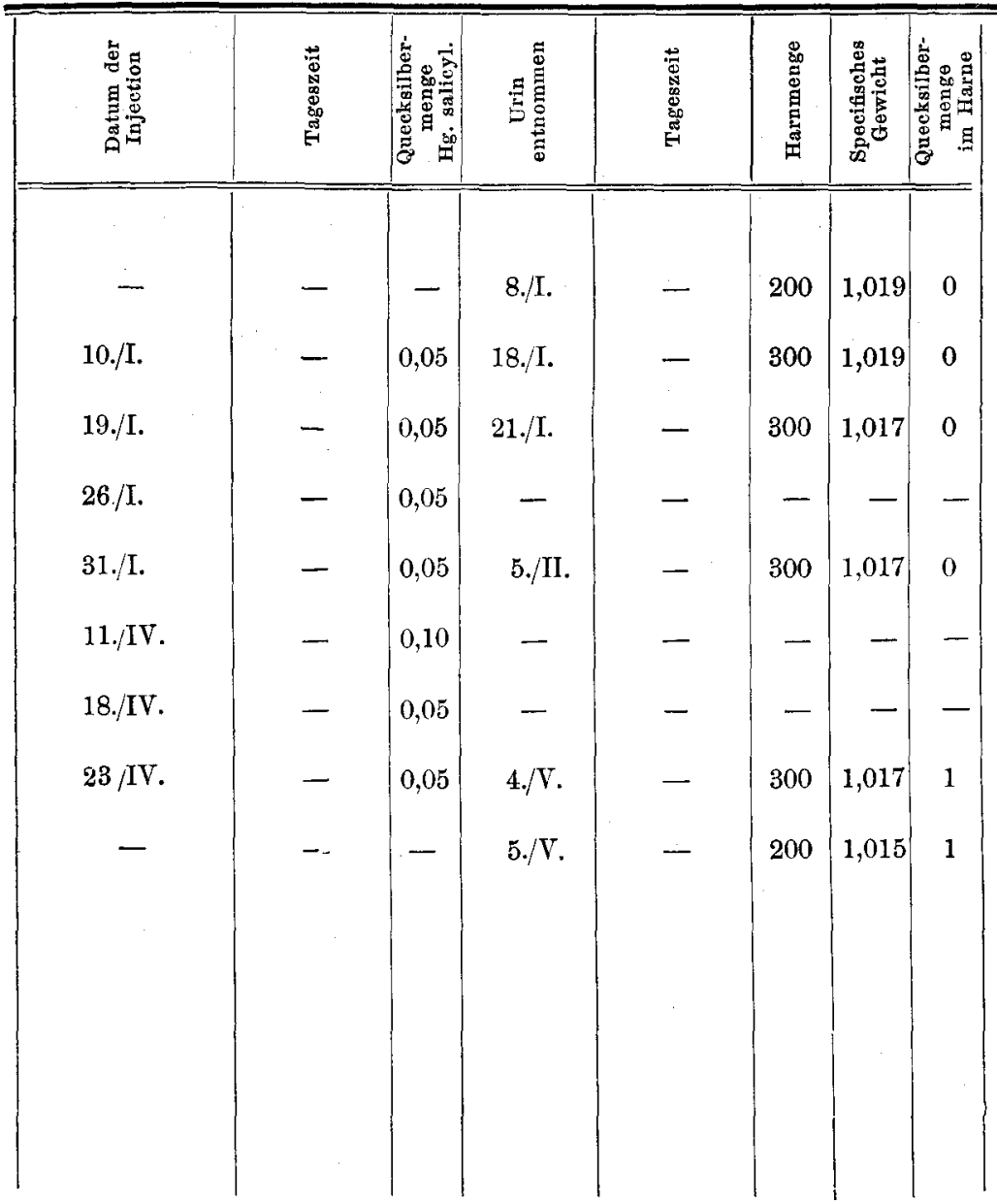

3 Wochen, nachdem innerhalb 4 Wochen 6 Injectionen von je 0.05 gemacht worden, keine Kugelchen. Ebenso konnte 2-5 und 8 Tage nach Inject. von 0.05 kein Quecksilber entdeckt werden. Nachdem im Laufe von 12 Tagen 3 Injectionen von zusammen $0 \cdot 20 \mathrm{Hg}$. salicyl. gemacht worden, 11 bis 12 Tage nach der letzten Injection wenig Quecksilber. 
Nr. 25.

A. 20 Jahre. Ulcus induratum penis. Adaenopatia inguinalis. Roseola syphilitica. Papulae mucosae faucium. Psoriasis.

Inject. 29. Jänner bis 23. Mai. Hg. salicyl 1·35. Innerliche Behandlung im Juli und August. Deutojod. Hg.

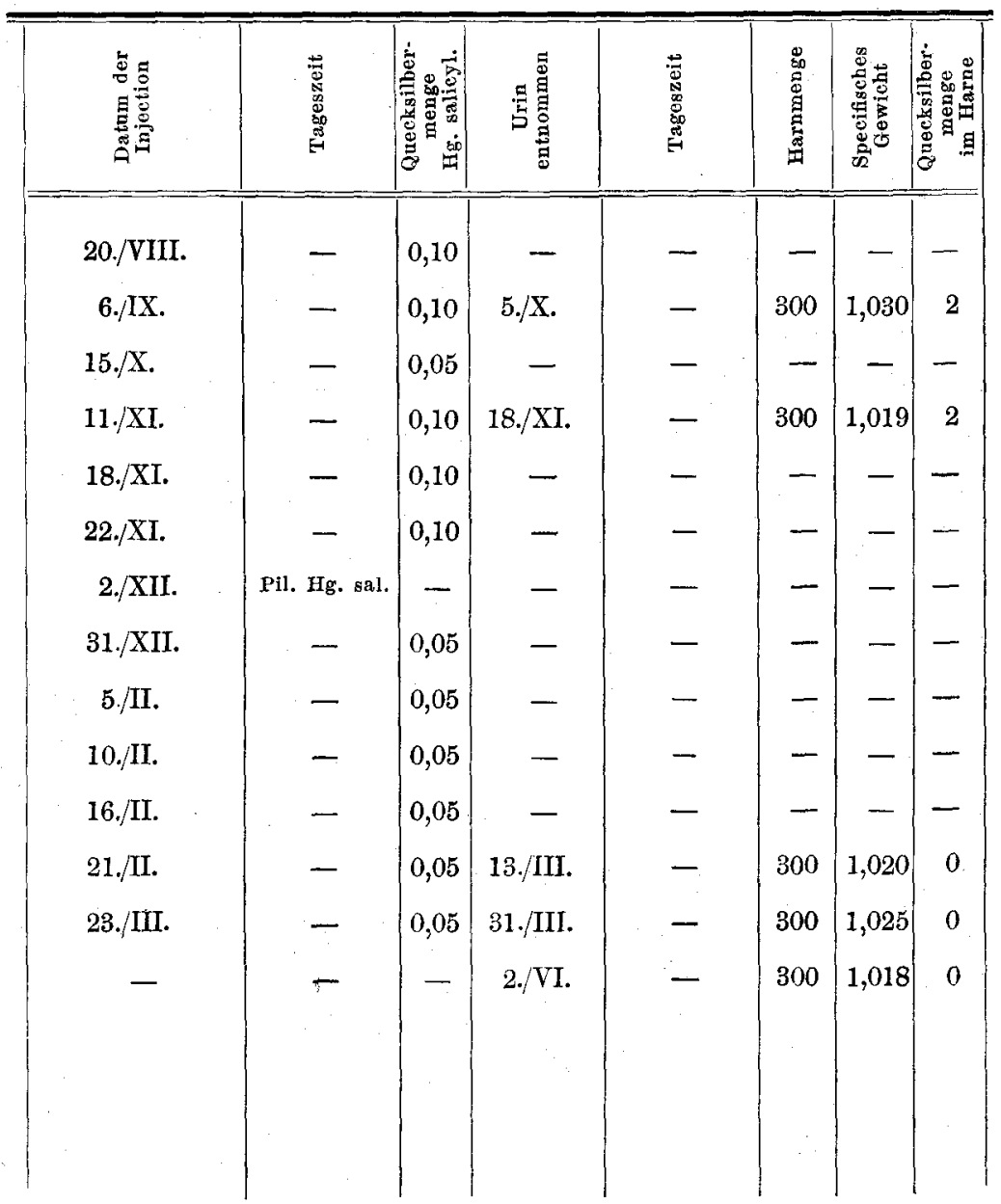

Hat ungefähr 2 Monate Deutojod. Hg. innerlich gebraucht und 2 Injectionen zu 0.10 Hg. salicyl. erhalten. 4 Wochen nach der letzten Injeetion recht grosse Menge Quecksilber. Eine Woche nach späterer Inject. recht viel. 3 Wochen nach 4 Injectionen von je 0.05 innerbalb 18 Tagen kein Quecksilber. Am 8. Tage und 10 Wochen nach der letzten Injection ebenfalls negatives Resultat. 
Untersuchungen über d. Resorption u. Eliminat. des Quecksilb. 203

Nr. 26.

S. 30 Jahre. Ulcus induratum penis. Adaenopatia inguinalis. Rosela syphilitica.

\begin{tabular}{|c|c|c|c|c|c|c|c|}
\hline 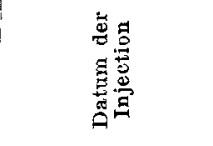 & 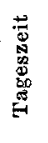 & 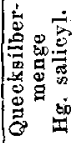 & 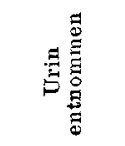 & 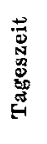 & 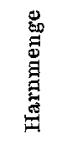 & 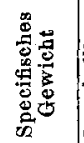 & 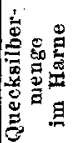 \\
\hline 28./III.-5./VI. & - & $\begin{array}{l}1,00 \\
\dot{e} d . \\
0,10\end{array}$ & 12./VI. & - & 200 & 1,015 & 2 \\
\hline 12./VI. & - & 0,10 & - & - & - & - & - \\
\hline 1./VII. & - & 0,05 & 2./VII. & - & 200 & 1,015 & 2 \\
\hline 9./VII. & - & 0,10 & 一 & - & 一 & 一 & 一 \\
\hline - & - & - & 10./VII. & - & 225 & 1,025 & 3 \\
\hline - & - & - & 1./VIII. & - & 200 & 1,025 & 1 \\
\hline- & - & - & 14./VIII. & - & 225 & 1,014 & 0 \\
\hline - & - & - & 8./IX. & - & 225 & 1,025 & 2 \\
\hline - & - & 一 & $17 . / \mathrm{X}$ & 一 & 250 & 1,020 & 0 \\
\hline $7 . / \mathrm{XI}$. & - & 0,05 & - & - & 一 & - & 一 \\
\hline 21./XI. & - & 0,05 & 2./XII. & - & 300 & 1,018 & 3 \\
\hline 2./ XII. & - & 0,05 & - & - & - & - & -- \\
\hline 15./XII. & - & 0,05 & 24./XII. & - & 250 & 1,027 & 0 \\
\hline 24./XII. & - & 0,05 & 6./LI. & 一 & 300 & 1,025 & 0 \\
\hline 一 & - & - & 7./II. & - & 200 & 1,020 & 0 \\
\hline - & - & 一 & 21./II. & - & 300 & 1,017 & 0 \\
\hline
\end{tabular}

7 Tage nach Inject. von 1.00 innerhalb 10 Wochen ziemlich viel Quecksilber. Einen Tag nach der nächsten Inject. recht viel; 3 Wochen nach einer Inject. von $0 \cdot 10$ wenig Quecksilber, das 5 Wochen später verschwunden war, aber 2 Monate nach der letzten Inject. wieder auftrat. $3^{1 / 2}$ Monate nach der letzten Injection keine Kügelchen. $1^{1 / 2}$ Wochen nach 2 Inject. von 0.05 viel Quecksilber, aber 9 Tage uach 4 Inject. von 0.05 innerhaib 6 Wochen keine Kügelchen. 
Nr. 27.

H. 28 Jahre. Ulcus induratum penis. Roseola syphilitica. Papulae mucosae faucium.

Inject. 15. Aug. bis 28. Aug. Hg. salicyl. 0.30. 9. Sept. bis 15. Oct. Pillul. tägglich $0 \cdot 05$. Nr. 120 .

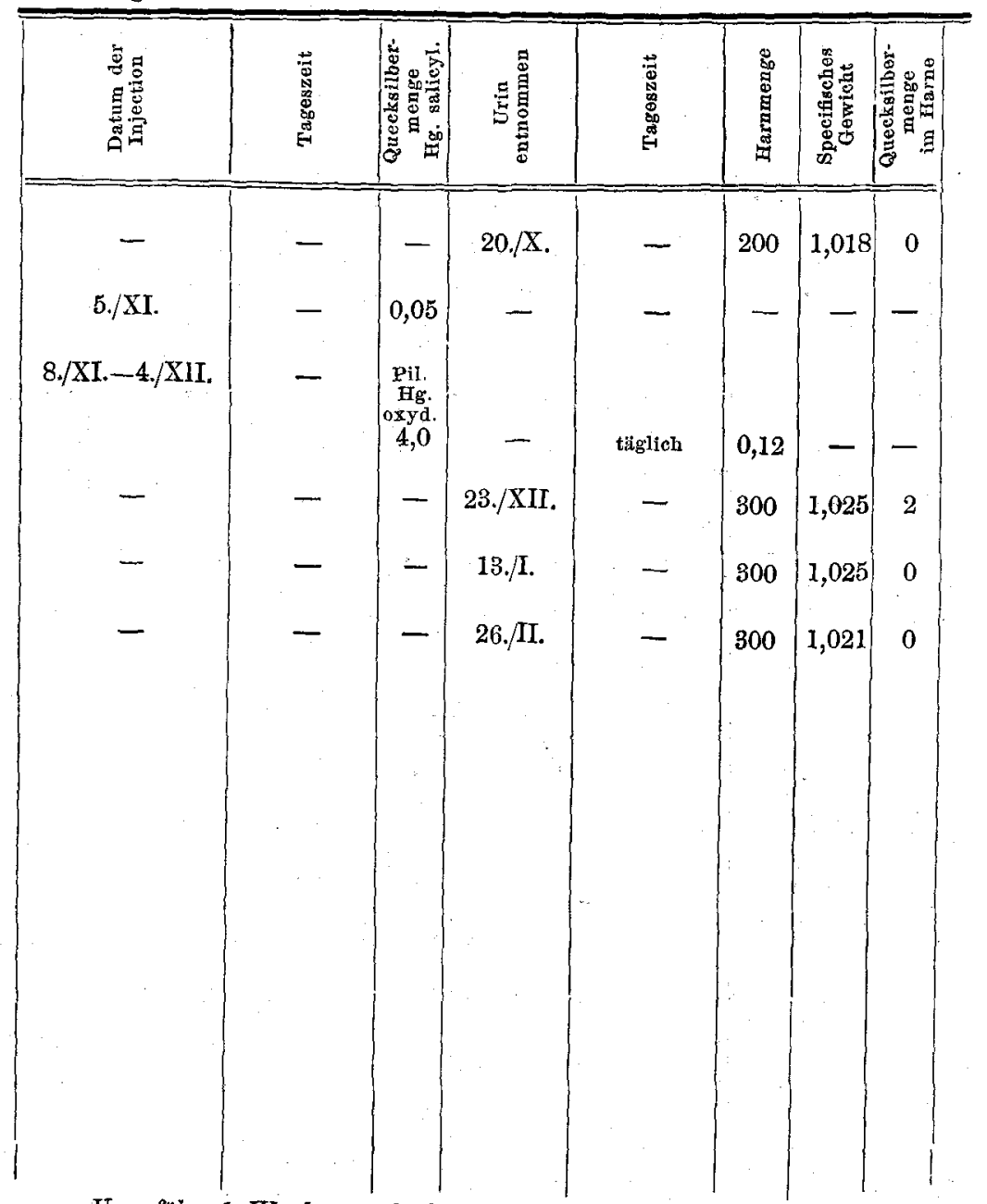

Ungefähr 1 Woche nach beendigter innerlicher Behandlung kein Quecksilber (nur 200 Gramm Urin). 19 Tage nach ebensolcher Behandlung recht viel Quecksilber im Urine; 6 Wochen nach der Behandlung Quecksilber verschwunden; ebenso bei einer späteren Untersuchung, 11 Wochen darauf. 
Untersuchungen über d. Resorption u. Eliminat. des Quecksilb. 205

Nr. 28.

R. 24 Jahre, Ulcus induratum penis. Adaenopatia inguinalis. Papulae mucosae faucium. Syphilis papulosa.

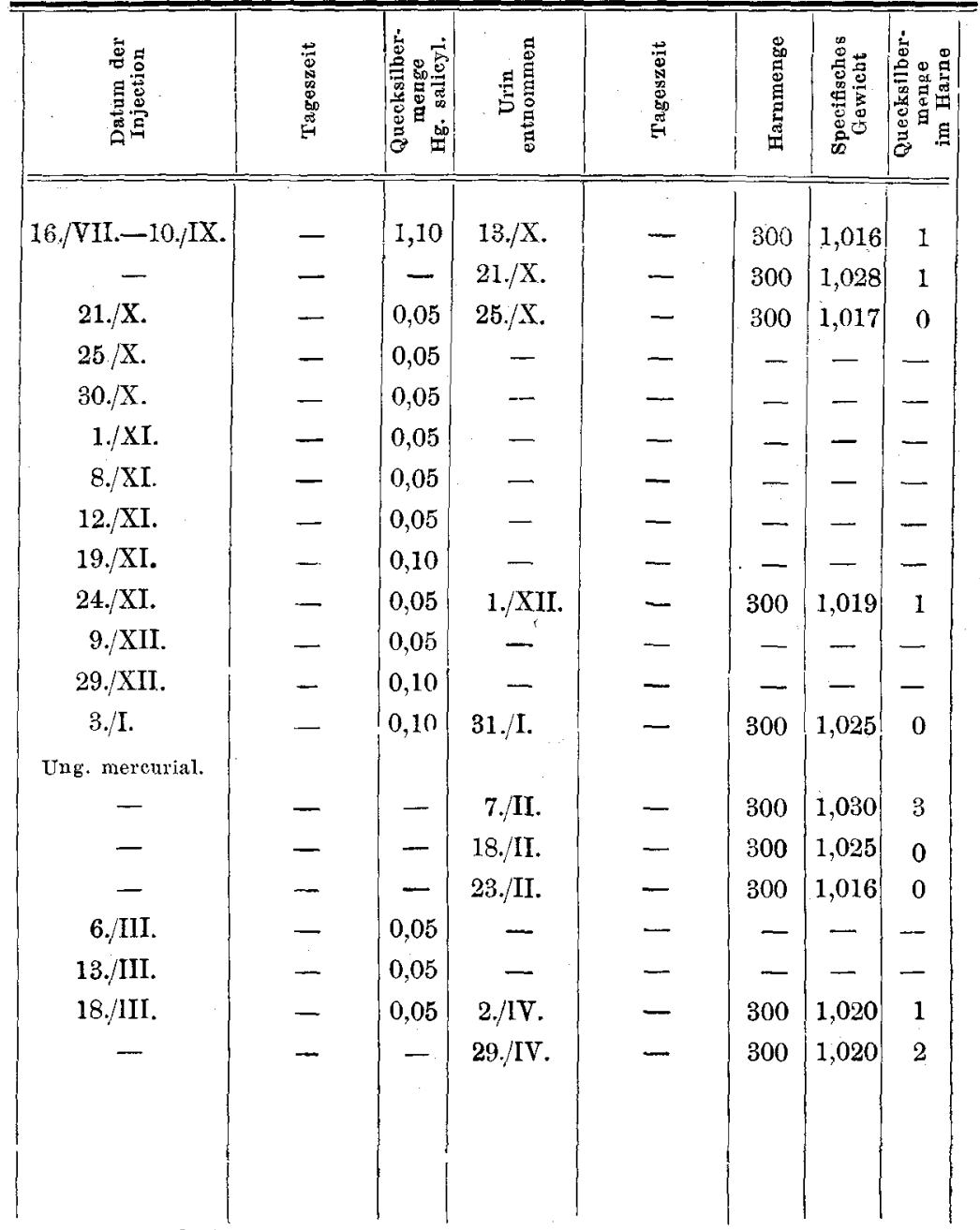

4-5 Wochen nach einer 7wöchentlichen Injectionscur mit zusammen 1.10 Hg. salicyl. wenig Quecksilber im Harne. 4 Tage nach einer Inject. von 0.05 kein Quecksilber. 1 Woche, nachdem 6 Inject. zu 0.05 und 1 Injection zu 0.10 gemacht worden, kein Quecksilber. 4 Wochen nach 2 Inject. 20 0.10 im Laufe von 5. Tagen keine Kügelchen. 2 Wochen nachdem 3 Inject. zu 0.05 innerhalb 2 Wochen gemacht worden, wenig Quecksilber; nach 6 Wochen ziemlich viel. 
Nr. 29.

L. 23 Jahre. Ulcus induratum penis. Adaenopatia inguinalis. Roseola syphilitica. Alopaecia.

\begin{tabular}{|c|c|c|c|c|c|c|c|}
\hline 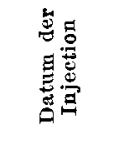 & 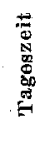 & 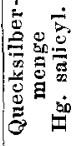 & 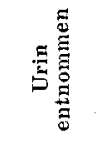 & 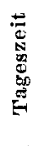 & 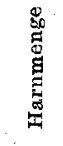 & 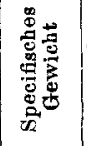 & 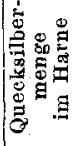 \\
\hline 4. $\mathrm{X}$. & - & 0,05 & - & - & - & - & - \\
\hline $14 . / \mathrm{X}$ & - & 0,05 & $20 . / X$ & - & 300 & 1,027 & 1 \\
\hline- & - & - & 25. $/ \mathrm{X}$. & - & 300 & 1,020 & 0 \\
\hline $25 . / \mathrm{X}$. & - & 0,05 & - & - & - & - & - \\
\hline 4./XII. & - & 0,05 & 一 & - & - & - & - \\
\hline 11./XII. & - & 0,05 & - & - & - & - & - \\
\hline 19./XII. & - & 0,05 & - & - & - & - & - \\
\hline 23./XII. & - & 0,05 & - & - & - & - & - \\
\hline $2 . / \mathrm{I}$. & - & 0,05 & $17 . / \mathrm{I}$. & - & 300 & 1,019 & 0 \\
\hline $17 . / \mathrm{I}$. & - & 0,05 & $24 / I I$ & - & 200 & 1,018 & 0 \\
\hline $24 . / \mathrm{II}$. & - & 0,05 & 10./III. & - & 300 & 1,020 & 1 \\
\hline 3./III. & - & 0,05 & - & - & - & - & - \\
\hline 10./III. & - & 0,05 & - & - & - & 一 & - \\
\hline 19./III. & - & 0,05 & 8./IV. & - & 300 & 1,022 & 1 \\
\hline- & - & - & 4./V. & - & 250 & 1,018 & 0 \\
\hline $4 . / \mathrm{V}$. & - & 0,05 & - & - & - & - & - \\
\hline & & & & & & & \\
\hline
\end{tabular}

6 Tage, nachdem innerhalb 10 Tagen 2 Inject. zu 0.05 gemacht worden, wenig Quecksilber im Harne, das 11 Tage später verschwnnden war. 2 Wochen nach 5 Inject. zu 0.05 innerhalb I Monats kein Quecksilber, ebenso 1 Woche nach einer darauf folgenden Injection. Spuren von Quecksilber fanden sich 2 Wochen nach 2 innerhalb 1 Woche gemachten In. jectionen und ebenso 3 Wochen nach 3 innerhalb 16 Tagen gemachten Inject. zu 0.05, Nach 6 $\frac{1}{2}$ Wochen war das Quecksilber verschwunden. 
Untersuchungen über d. Resorption u. Eliminat. des Quecksilb. 207 Nr. 30 .

S. 28 Jahre. Laryngitis chronica ulcerosa. Ulcera nasi et capitis.

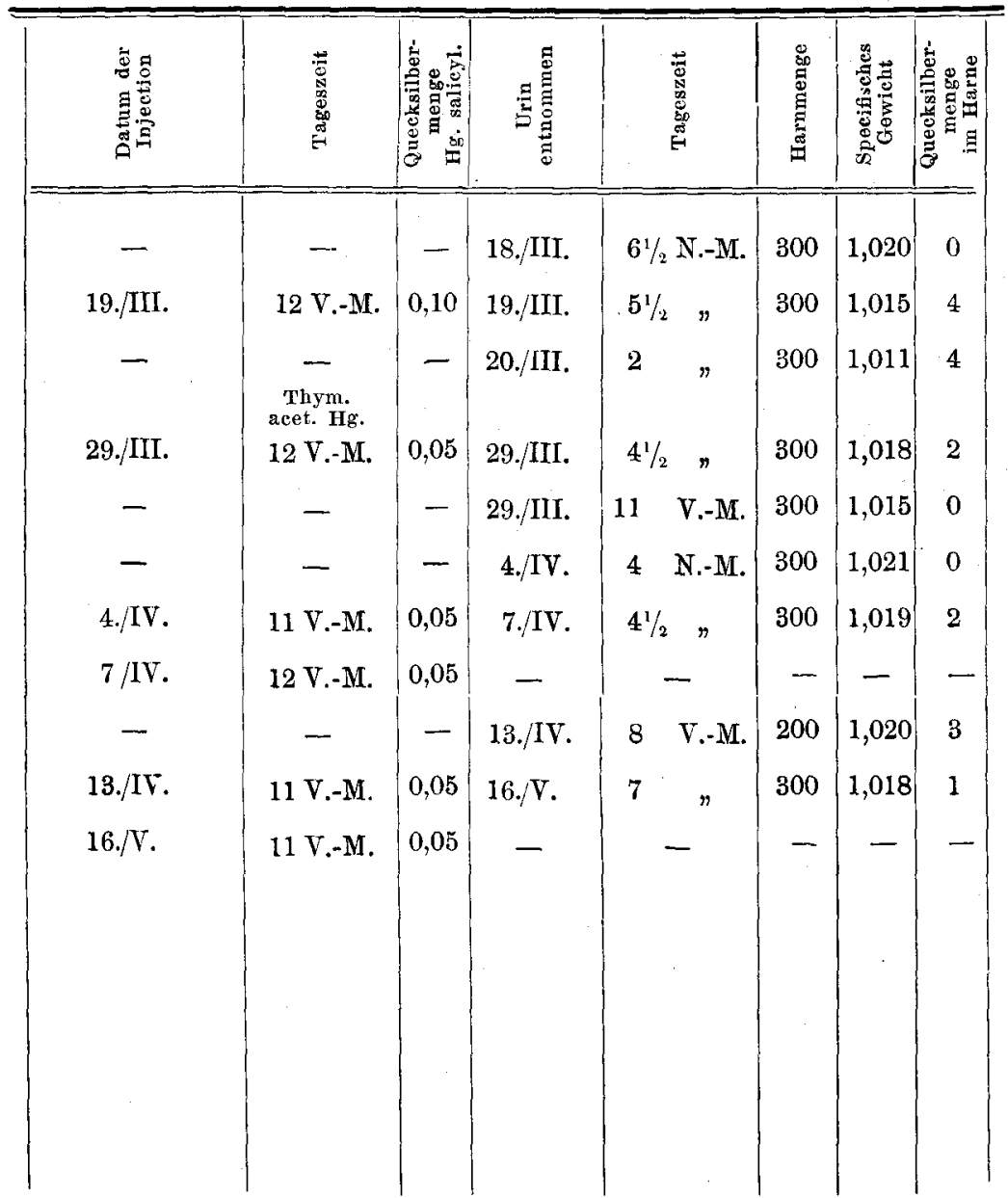

51/2 Stunden nach Inject. von Hg. salicyl. 0.10 viel Quecksilber im Harne, das sich noch 10 Tage später vorfand; nach darauf folgender Injection von Thym. acet. Hg. 005, sowohl 11 Stunden wie 6 Tage später kein Quecksilber (möglicherweise auf einer nach der Inject. entstandeneu Induration beruhend). Drei und fünf Tage nach darauf folgenden gleichen Injectionen wieder recht viel Quecksilber. 1 Monat nach der letzten Injection Spuren von Quecksilber. 
Lindén.

Nr. 31.

T. 22 Jahre. Papulae mucosae ani.

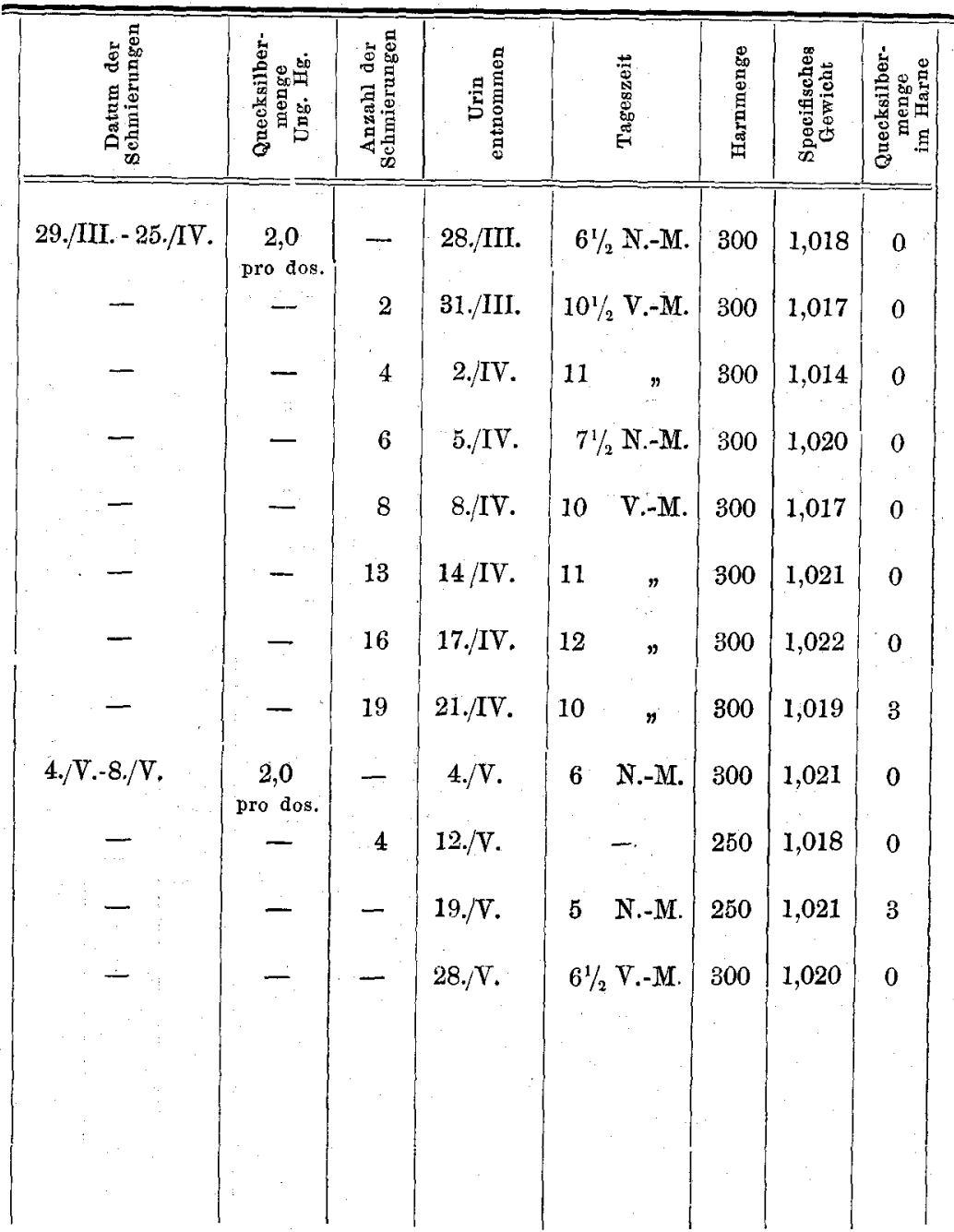

Vor der Cur kein Quecksilber im Harne. 19 Tage nach Beginn der Schmiercur in Dosen von $2 \cdot 0$ Ung. Hg. kein Quecksilber. Am 23. Tage grosse Menge Kügelchen im Urin. 9 Tage nach beendigter Schmiercur kein Quecksilber. Nach einer Pause von 2 Wochen und nachdem wieder 4 Päckchen zu 2.0 eingexieben worden, zeigte sich am 4. Tage noch kein Quecksilber. Am 11. Tage nach beendeter Cur wieder Quecksilber, das am 20. Tage verschwunden ist. 
Nr. 32.

N. 23 Jahre. Papulae mucosae faucium scroti et ani. Adadenopatia inguinalis. Laryngitis.

\begin{tabular}{|c|c|c|c|c|c|c|c|}
\hline 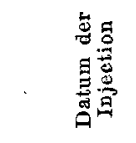 & 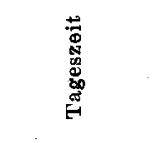 & 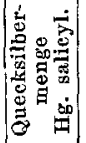 & 莒总 & 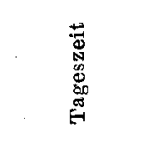 & 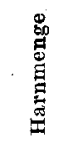 & 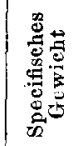 & 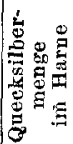 \\
\hline - & - & - & 16./III. & $2^{1 / 2}$ N.-M. & 300 & 1,013 & 0 \\
\hline 7./III. & $11^{1} / 2$ V.-M. & 0,10 & 17./III. & 2 & 300 & 1,010 & 3 \\
\hline - & - & - & 17./III. & 8 & $\$ 00$ & 1,011 & 4 \\
\hline- & - & - & 18./III. & $6^{1 / 2} \quad n$ & 300 & 1,012 & 4 \\
\hline - & 一 & - & 20./III. & $5^{12}$ & 300 & 1,014 & 1 \\
\hline 一 & 一 & - & 21./IIT. & 6 & 300 & 1,012 & 0 \\
\hline - & _- & - & 22./III. & 6 & 300 & 1,010 & 1 \\
\hline _- & _ & - & 23./III. & 6 & 300 & 1,010 & 0 \\
\hline - & - & - & 25./III. & 9 & 300 & 1,011 & 1 \\
\hline - & - & - & $26 . / I I J$. & 7 & 300 & 1,010 & 0 \\
\hline - & - & - & 27./III. & 5 & 300 & 1,012 & 0 \\
\hline - & - & $\left|\begin{array}{c}-\overline{\text { Thymm }} \\
\text { acet. }\end{array}\right|$ & 28./III. & 6 & 300 & 1,012 & 0 \\
\hline 29./III. & $10^{1} / 2$ V.-M. & $\begin{array}{l}\mathrm{Hg} \cdot \mathrm{.} \\
0,05\end{array}$ & 29./III. & 11 & 300 & 1,012 & 1 \\
\hline- & - & - & $3 . / \mathrm{IV}$ & 6 & 300 & 1,010 & 0 \\
\hline 4./IV. & - & 0,05 & 6/IV. & $6 \quad n$ & 300 & 1,025 & 2 \\
\hline & 一 & - & 11./IV. & $111 / 2$ V.-M. & 300 & 1,019 & 0 \\
\hline - & - & - & 13./IV. & $10^{3} \%$ & 300 & 1,017 & 2 \\
\hline 13./IV. & 11 V.-M. & 0,05 & 12./V. & - & 250 & 1,021 & 4 \\
\hline - & - & 一 & $24 . / \mathrm{V}$. & $6^{1} / 2$ V.-M. & 300 & 1,017 & 0 \\
\hline
\end{tabular}

Vor der Einspritzung kein Quecksilber im Urine. $2 \frac{1}{2}$ und $81 / 2$ Stunden nach Inject. von $0 \cdot 10$ grosse Menge Quecksilber, ebenso 1 und 3 Tage später; während der 4 darauf folgenden Tage theils wenig, theils ver schwunden, bis zum 9., 10. und 11. Tage. 11/2 Stunden nach der nächsten Injection von 0.05 wieder wenig Quecksilber, das 5 Tage darauf verschwand, um 2 Tage nach der folgenden Injection wieder aufzutreten und 7 Tage später zu verschwinden. Am 9. Tage wieder Quecksilber und 1 Monat nach der letzten Inject. viel Quecksilber, das 6 Wochen später verschwand. Dass nach der 2. und 3. Einspritzung kein Quecksilber anzutreften war, beruhte vielleicht auf der nach denselben eingetretenen Infiltration.

Der grösseren Uebersicht wegen in Betreff des mehr oder weniger schnellen Auftretens des Quecksilbers im Urin nach der Injection, wie seiner Permanenz, habe ich ausserdem die Analysen so gruppirt, dass alle Fälle, in denen nur eine Injection gemacht worden, in eine Gruppe zusammengestellt sind und alle übrigen in die zweite.

Ergänzungshefte z. Archiv f. Dermatol. u. Syphil. 1892. 
Analysen mit positivem Resultat nach einer einzigen Injection.

Nr. 15. 2 Std. nach Inject. von Hg. sal. 0,10. Quecks.-Menge 1

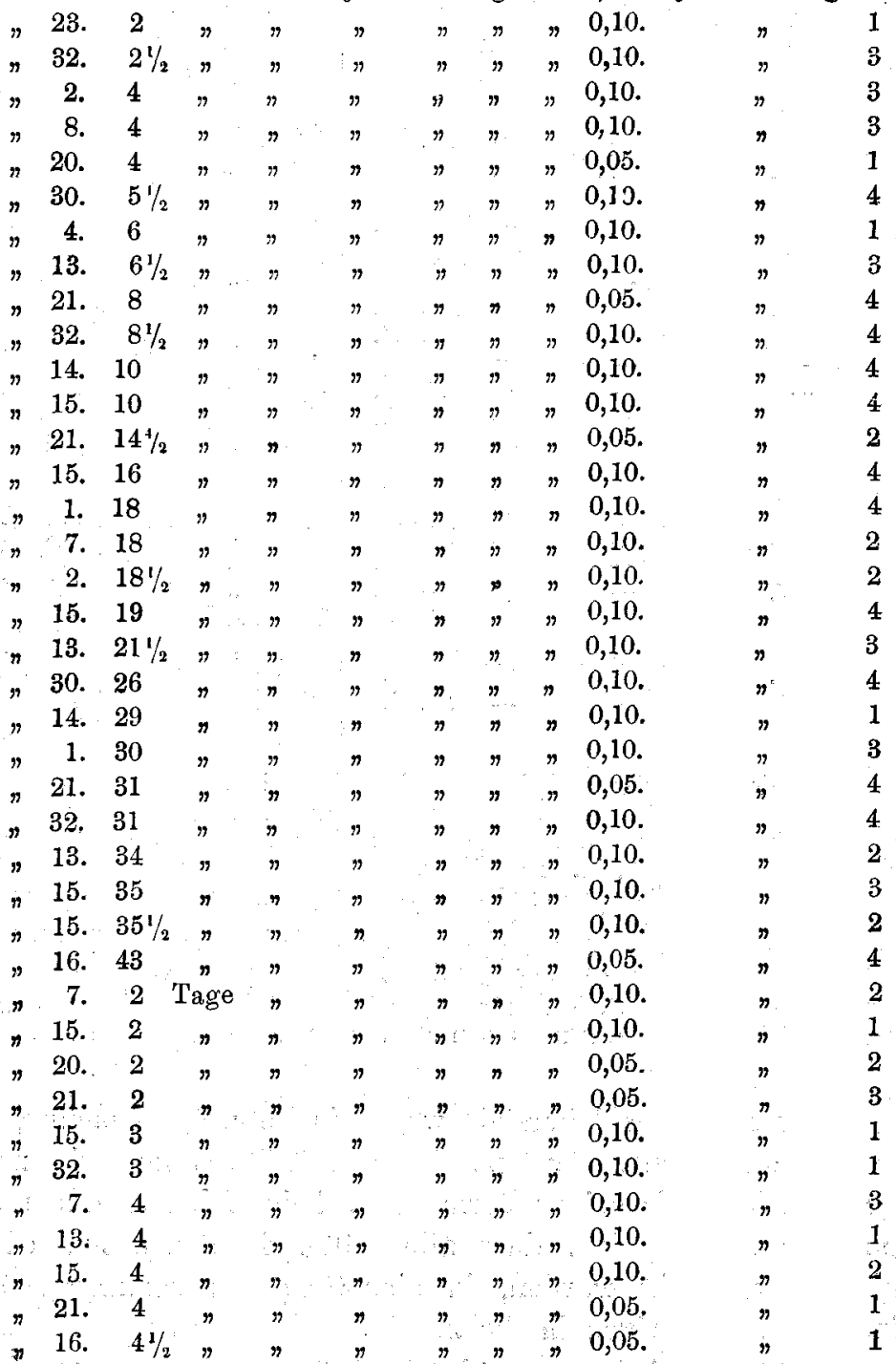


Untersuchungen über d. Resorption u. Eliminct des Quecksilb. 211

Nr. 32. 5 Std. nach Inject, von $\mathrm{Hg}$. sal. 0,10. Quecks.-Menge 1

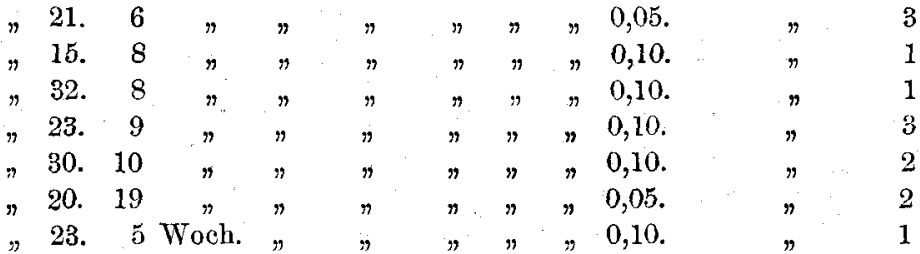

Analysen mit negativem Resultat nach einer einfachen Injection.

Nr. 32. 4 Tage nach Inject. von Hg. sal. 0,10. Kein Quecksilber.

\begin{tabular}{|c|c|c|c|c|c|c|c|c|c|c|}
\hline " 15. & 5 & $\eta$ & $\pi$ & $"$ & $"$ & $"$ & $"$ & 0,10 . & " & $n$ \\
\hline 32. & 6 & $"$ & $"$ & $"$ & $n$ & $"$ & $n$ & 0,10 . & $"$ & $n$ \\
\hline ก 21. & 8 & $\eta$ & in & $"$ & $"$ & $"$ & $n$ & 0,05 & $n$ & $n$ \\
\hline " 21. & 8 & $\eta$ & $"$ & $"$ & $n$ & $"$ & $n$ & 0,05 . & $"$ & $n$ \\
\hline 32. & 9 & $\eta$ & $"$ & $n$ & $"$ & $\eta$ & $n$ & 0,05 . & $"$ & $n$ \\
\hline 32. & 10 & $"$ & $"$ & $"$ & $\Rightarrow$ & $n$ & $"$ & 0,05 & $\pi$ & $n$ \\
\hline 32. & 10 & $"$ & $n$ & $n$ & $n$ & $"$ & $\pi$ & 0,10 . & $n$ & $n$ \\
\hline 21. & 12 & $"$ & $"$ & $"$ & $n$ & $\eta$ & $\eta$ & 0,10 . & $\eta$ & $"$ \\
\hline 21. & 14 & $"$ & $"$ & $\pi$ & $"$ & $"$ & $"$ & 0,10 & $\eta$ & $\eta$ \\
\hline 23. & 14 & $n$ & $n$ & $n$ & $\pi$ & $n$ & $"$ & 0,10 . & $n$ & $\eta$ \\
\hline " 21. & 19 & $n$ & $"$ & ” & $"$ & $n$ & $\eta$ & 0,10 . & $\eta$ & $n$ \\
\hline 22. & 19 & $"$ & $"$ & $"$ & $"$ & $"$ & $n$ & 0,10 . & $"$ & $"$ \\
\hline 23. & 24 & $n$ & $"$ & $n$ & $n$ & $"$ & $"$ & 0,10 . & $n$ & $n$ \\
\hline 21. & 4 & Wochen & $n$ & $"$ & $\eta$ & $"$ & $\eta$ & 0,05 . & $n$ & $"$ \\
\hline 21. & 4 & $\eta$ & $"$ & $"$ & $"$ & $"$ & $n$ & $0,10$. & $n$ & $n$ \\
\hline 23. & 6 & $\eta$ & $"$ & $\eta$ & $n$ & $\eta$ & $n$ & 0,10 . & $n$ & $n$ \\
\hline 17. & 7 & $n$ & $"$ & $"$ & $"$ & $n$ & $"$ & 0,10 & $"$ & $"$ \\
\hline 23. & 9 & $\eta$ & $"$ & $n$ & $"$ & $\eta$ & $\pi$ & 0,10 . & $n$ & $"$ \\
\hline 23. & $21 / 2$ & $=$ Monat & $"$ & $"$ & $"$ & $"$ & $n$ & 0,10 . & $n$ & $"$ \\
\hline 23. & 4 & $\eta$ & $"$ & 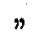 & $n$ & $n$ & $"$ & 0,10 . & $n$ & $n$ \\
\hline
\end{tabular}

Aus dieser Zusammenstellung geht hervor, dass 48 Quecksilheranalysen nach einer einmaligen Injection von $\mathrm{Hg}$. salicyl. gemacht worden sind, in 37 Fällen in einer Dosis von $0 \cdot 10$ und in 11 Fällen 0.05 und zwar an Harn von Patienten, die früher in keiner Form Quecksilber erhalten hatten oder solchen, die vor längerer Zeit dasselbe gebraucht hatten, deren Harn sich aber bei der Untersuchung als ganz quecksilberfrei erwiesen hatte. 
Der früheste Termin, in dem nach einer einfachen Injection von Hg. salicyl. 0.10 Quecksilber im Harne nachgewiesen werden konnte, war in 3 Fällen $2-2 \%$. Stunden der kürzeste Zeitraum, in dem eine Harnmenge von $300 \mathrm{Ccm}$. zu erhalten war, nachdem die Blase vor der Injection entleert worden. In den beiden ersten Fällen enthielt der Harn nur eine geringe Menge, im 3. eine grössere Menge Quecksilber. Innerhalb der nächsten 10 Stunden nach der Injection zeigte sich die Quecksilberquantität im Urin in starkem Steigen, so dass dieselbe, von 10 Untersuchungen an 10 verschiedenen Patienten, in 8 Fällen als sehr hoch bezeichnet werden muss, nur in 2 Fällen war sie gering. In einem dieser Fälle wurde nur eine Injection von 0.05 gemacht; in einem anderen Falle enthielt der Urin 8 Stunden nach der Injection eine sehr grosse Menge Quecksilber, trotzdem nur 0.05 injicirt wurden. In den darauf gemachten Untersuchungen, 14-21 Stunden nach der Injection, war die Quecksilberquantität hoch, nur in 3 Fällen war sie niedrig.

Während des zweiten Tages hielt sich die Quecksilbermenge, wenngleich etwas im Abnehmen, doch noch hoch: von 13 Untersuchungen an 11 Fällen war die Quecksilbermenge in 7 Fällen hoch in 6 Fällen niedrig.

Innerhalb des 3., 4., 5. und 6. Tages zeigt das Quecksilber starke Abnahme: von 9 Untersuchungen an ebenso vielen Fällen konnte in 6 Fällen nur eine geringe Menge Quecksilber nachgewiesen werden und in 3 Fällen eine böhere.

Wo Quecksilber angetroffen werden konnte, nachdem längere Zeit seit den Injectionen verflossen war, war die Quantität auch gering. Die längste Zeit in der nach einer einfachen Injection mit Sicherheit Quecksilber nachzuweisen war, betrug 19 Tage in 1 Falle; in den übrigen 5 Fällen variirte die Zeit zwischen 8-10 Tagen und war die Quantität nur einmal über Mittelmenge.

Auch in allen den Fällen, wo die Analyse nach einer einfachen Injection negative Resultate ergab, war der Urin durch vorherige Untersuchung als quecksilberfrei constatirt worden. Die Zahl der Analysen in dieser Gruppe betrug 21 und die Dosis Hg. salicyl. 0.10 oder 0.05. 
In zwei Fällen, Nr. 15 und 32, wo 3 Analysen gemacht wurden, war das Quecksilber schon am 4., \%. und 6. Tage nach Injection von 0.10 verschwunden; in Nr. 15 konnte dieser Umstand vielleicht mit dem niedrigen spec. Gewicht des Harnes in Zusammenhang stehen. In Nr. 32 trat das Quecksilber sehr schnell und in grosser Menge im Urin auf, was aus der $\mathrm{Zu}$ sammenstellung der positiven Analysen herrorgeht, nahm am 3. Tage schnell wieder ab, so dass es rom 3. bis 9. Tage entweder in geringer Menge sich zeigte oder fehlte; am 9., 10. und 11. Tage war es ganz verschwunden. Innerhalb der zweiten Woche nach der Injection sind 8 Analysen gemacht worden; in 4 Fällen betrug die Dosis 0.10 und in ebenso vielen Fällen 0.05 ; in keinem Falle wurde Quecksilber gefunden.

5 Analysen sind nach Verlauf von 3 und 4 Wochen gemacht worden und ebenso 5 Analysen, nachdem 10 und 16 Wochen seit der Injection verflossen, und in keinem dieser Fälle konnte Quecksilber nachgewiesen werden.

Hieraus würde also hervorgehen, dass das Quecksilber wach einer einfachen Injection von 0.10 oder $0.05 \mathrm{Hg}$. salicyl. sehr schnell resorbirt wird, so dass es schon nach einigen Stunden im Harne anzutreffen ist; die Quecksilbermenge steigt dann innerhalb der ersten 12 Stunden sehr schnell, so dass grosse Quantitäten davon anzutreffen sind, hält sich während des ersten und zweiten Tages recht hoch, nimmt dann während der folgenden Tage wieder schnell $a b$, so dass es im Harn nur in Mittelmenge nachzuweisen oder bisweilen auch schon ganz verschwunden ist. Obgleich das Quecksilber bisweilen auch später nachgewiesen werden kann, dürfte es nach einer einfachen Injection gewöhnlich am Schluss der ersten oder im Beginn der zweiten Woche aus dem Körper ausgeschieden sein.

\section{Analysen mit positivem Resultat nach mehreren Injectionen.}

3. 1 Std. n. Inj. v. Hg. sal. 1,30 innerh. $4 \frac{1}{2}$ Mon. in Dos. 0,10. Q.-M. 4 16. 4 " " " " 0,10 " 4 Tag. " $0,05 . " 4$

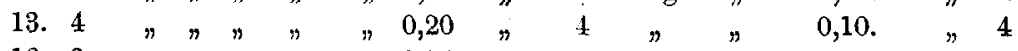

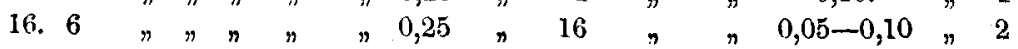


$\mathrm{Nr}$.

16. 6 Std. n. Inj. v. Hg. sal. 0,45 innerh. 36 Tag. in Dos. 0,05-0,10. Q.-M. 4

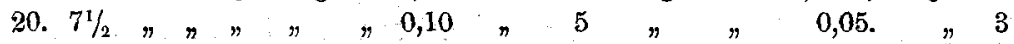

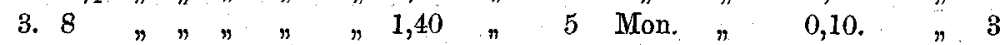

16. $81 / 2 " \# " \# " 0,15 " 11$ Tag. " $" 0,05$. " 2

3. $9 \frac{1}{2} ", ", ", 1,30 "$ " $" 4 \frac{1}{2}$ Mon. " $\quad 0,10$. " 4

32. $11^{1 / 2}, ", ", \quad, 1,10$

20.17 Th. ac. Hg. 0,05

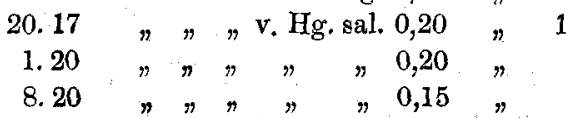

7. 1 Tag. $" n$ " $, 0,20$

13. $1, " n, " n, 0,30$

16. $1 " \Rightarrow " \Rightarrow " n, " n$

23. 1 " " " " " " $" 1,45$

26. 1 " n $n, n 1,15$

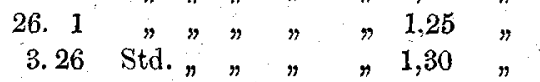

$15.26 " \# " n, \quad " 0,50$

15.27 " $n \quad n \quad n \quad n, 30$

$18.291 / 2, " n, " n \quad ", 0,30$

$3.331 / 2 " \Rightarrow " \Rightarrow, \quad " 1,50$

$15.33 \mathrm{t} / 2 " n " n, 0,20$

$3.43 n " n n n 1,00$

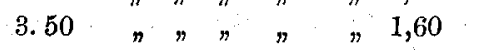

3. 2 Tag. $" \#, \quad " 1,30$ :

7. $2 " n " n \quad " \quad, 0,20$

15. 2 " $n \quad n \quad n \quad, \quad n, 40$

15. 2 " " " " " $" 0,20$

32. $2 "$ " "Th. ac. Hg. 0,10

15. $2 \frac{1}{2}, n \quad n$ v. Hg. sal. 0,20

16. 3 " $n " n \quad 0,35$

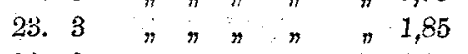

30. $3 n " n, ", 0,10$

12 Tag. n $\quad 0,05 . \quad \cdots 1$

$12 " \quad " \quad 0,05 . \quad 74$

$3 n " 0,10 . \quad " 4$

$2 \frac{1}{2}$ Woch. $" \quad 0,10$. " 4

5 Tag. " $0,10$. " 4

$9 " \quad 0,10 . \quad 74$

36 " $\quad 0,05-0,10 \Rightarrow 3$

4 Mon. : " $0,05-0,10$ " 4

$3 " n \quad 0,05-0,10 " 2$

$3 \%$ " " $\quad 0,05-0,10 \quad " \quad 3$

$4 \frac{1}{2} \quad " \quad 0,10 . \quad \Rightarrow 3$

16 Tag. $n$ 0,10. \#4

$9 \quad " \quad 0,10 . \quad$ " 4

$8 \% " \quad 0,10 . \quad " \quad 3$

5 Mon. " 0,10 . " 4

4 Tag. " $0,10$. " 2

13 Woch. " 0,10. " 3

$51 / 2$ Mon. " 0,10 . " 4

$4 \frac{1 / 2}{4} \quad " \quad 0,10 . \quad \cdots 3$

4 Tag. " 0,10 ., 3

$14 " \quad \Rightarrow \quad 0,10 . \quad \% 3$

10 " $\quad 0,10$. " 2

$18 \quad " \quad " \quad 0,05 . \quad 2$

$4 \quad " \quad 0,10 . \cdots 1$

21 Woch. $\# \quad 0,10 ., \cdots=2$

Th. ac. Hr. 0,10 " 16 Tag. " $\quad 0,05 . \quad$ " 2

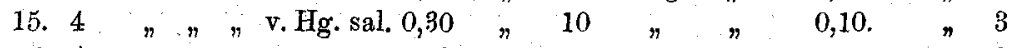

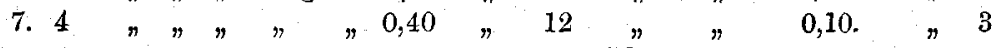

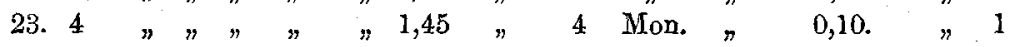

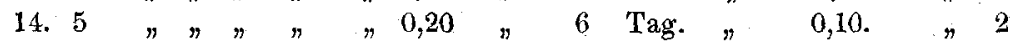

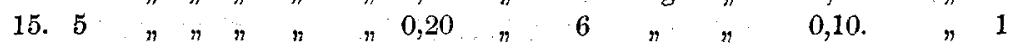

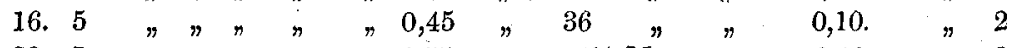

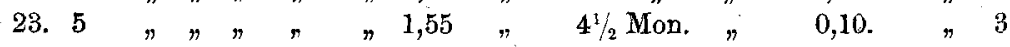

23. 5 " " " ", $95 \% 21$ Woch. " $0,10 . \quad 3$

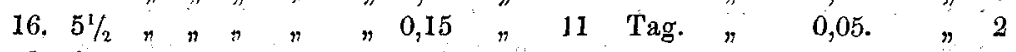

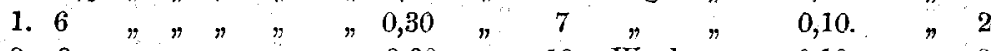

3. 6 " " " " $" 0,90 " 13$ Woch. $" \quad 0,10$. $" 3$

15. 6 " " " " " $" 0,40$ " 14 Tag. " 0,10 . " 1 
Untersuchungen über d. Resorption u. Eliminat. des Quecksilb. 215

29. 6 Tag. n. Inj. v, Hg, sal. 0,10 innerh. 10 Tag. in Dos. 0,05. Q.-M. I 30. 6 " " " $, 0,10$

\begin{tabular}{|c|c|c|c|c|c|c|c|c|c|c|c|c|c|}
\hline & & & & & & & & & & & & & \\
\hline 0.7 & $n$ & $\eta$ & $n$ & v. $\mathrm{Hg}$ & sal. & 0,35 & $\eta$ & 4 & Woch. & • " & $0,05-0,10$ & 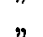 & \\
\hline ). 7 & $n$ & $n$ & $"$ & $n$ & $n$ & 0,95 & $n$ & $31 / 2$ & Mon. & $n$ & $0,05-0,10$ & & \\
\hline 5. 7 & $n$ & $n$ & $\eta$ & $n$ & $n$ & 0,25 & $n$ & 11 & Woch. & $n$ & $0,05-0,10$ & & \\
\hline 1. 7 & $n$ & $n$ & $\eta$ & $n$ & $n$ & 0,40 & $n$ & 5 & Mon. & 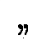 & $0,05-0,10$ & & \\
\hline 3. 7 & $"$ & $n$ & $"$ & $\eta$ & $"$ & 2,05 & 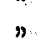 & $5 \%$ & n & $n$ & $0,05-0,10$ & & \\
\hline b. 7 & $n$ & 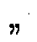 & $n$ & $n$ & $"$ & 1,00 & $n$ & 9 & Woch. & $n$ & 0,10 & & \\
\hline 8. 7 & $\pi$ & $n$ & $n$ & $n$ & $n$ & 1,55 & $n$ & 15 & $n$ & $n$ & $0,05-0,10$ & ข & \\
\hline 6. 8 & $\eta$ & $\eta$ & $»$ & $\eta$ & $"$ & 0,35 & $"$ & 21 & Tag. & 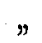 & $0,05-0,10$ & & \\
\hline 3. 9 & $n$ & $n$ & 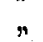 & $n$ & $n$ & 0,40 & $\eta$ & 17 & ” & $n$ & 0,10 . & & \\
\hline 3. 9 & 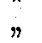 & $\eta$ & $\eta$ & $"$ & $\eta$ & 2,15 & $"$ & 24 & Woch. & 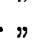 & 0,10 & & \\
\hline 2. 9 & $n$ & $n$ & $n$ & $n$ & $n$ & 0,10 & & & & & & & \\
\hline & & & u. ' & 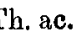 & $\mathrm{Hg}$. & 0,10 & $n$ & 18 & Tag. & $"$ & $0,05-0,10$ & $n$ & \\
\hline 1. 9 & $"$ & $\eta$ & $\eta$ & v. $\mathrm{Hg}$ & sal. & 0,60 & $\eta$ & 4 & Woch. & $n$ & 0,10 . & 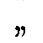 & \\
\hline 2.10 & $n$ & $n$ & $n$ & $n$ & $\eta$ & 0,30 & & 9 & Tag. & $n$ & 0,10 . & & \\
\hline 2. 10 & $n$ & $n$ & $\eta$ & $n$ & $"$ & 0,60 & $\eta$ & 9 & Woch. & $n$ & 0,10 . & & \\
\hline 13. 10 & , & $"$ & $"$ & $\eta$ & $"$ & 1,65 & $"$ & $4^{1} \%$ & ${ }_{2}$ Mon. & $n$ & $0,05-0,10$ & & \\
\hline 3.11 & $"$ & $n$ & $\eta$ & $\eta$ & $\eta$ & 1,50 & $n$ & 5 & $n$ & $n$ & 0,10 . & $\eta$ & \\
\hline 4.11 & $n$ & $n$ & $"$ & $"$ & $"$ & 0,20 & $n$ & 12 & Woch. & $n$ & $0,05-0,10$ & & \\
\hline 26. 11 & 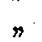 & $\eta$ & $\eta$ & 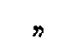 & $"$ & 0,10 & $"$ & 2 & Woch. & . & 0,05 . & $n$ & \\
\hline 3. 12 & $"$ & $n$ & $n$ & $"$ & $"$ & 1,00 & $n$ & 13 & $"$ & $n$ & 0,10 & , & \\
\hline 24.12 & $n$ & $n$ & $"$ & $n$ & $n$ & 0,20 & " & 12 & Tag. & $n$ & $0,05-0,10$ & $n$ & \\
\hline 16. & $"$ & $n$ & $"$ & $"$ & $"$ & 0,55 & $"$ & 41 & $n$ & $n$ & $0,05-0,10$ & & \\
\hline 1.13 & $n$ & $n$ & $\eta$ & $"$ & n & 0,40 & 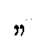 & 2 & Woch. & $n$ & 0,10 & $"$ & \\
\hline 3. 14 & $n$ & $n$ & $n$ & $"$ & $"$ & 1,00 & $\eta$ & 13 & $\eta$ & $n$ & 0,10 . & $n$ & \\
\hline 15. 14 & $n$ & $n$ & $n$ & $n$ & $"$ & 0,40 & $n$ & 14 & Tag. & $n$ & 0,10 . & $n$ & \\
\hline 92.13 & $n$ & $n$ & $\eta$ & $"$ & $n$ & 0,35 & $\eta$ & 3 & Mon. & $\eta$ & 0,05 . & . & \\
\hline 20.14 & $\eta$ & $n$ & $\eta$ & $n$ & $\eta$ & 0,15 & $"$ & 12 & Tag. & $n$ & 0,05 . & $\eta$ & \\
\hline 23.14 & $n$ & $m$ & $n$ & $n$ & $n$ & 2,15 & $"$ & 24 & Woch. & $\cdot n$ & 0,10 . & $n$ & \\
\hline 28.14 & $n$ & $n$ & $n$ & $n$ & $n$ & 0,15 & $n$ & 2 & Tag. & $n$ & 0,05 . & $n$ & \\
\hline 7.15 & 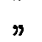 & $\eta$ & $n$ & $"$ & $n$ & 0,50 & $n$ & 16 & $"$ & $"$ & 0,10 & 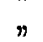 & \\
\hline 20.16 & $\eta$ & $n$ & $"$ & $"$ & $n$ & 0,85 & $\eta$ & 3 & Mon. & $n$ & 0,10 . & $n$ & \\
\hline 23.17 & $n$ & $n$ & $n$ & \% & $n$ & 1,75 & $\eta$ & 19 & Woch. & . $"$ & $0,05-0,10$ & $\eta$ & \\
\hline 7. 19 & $\eta$ & $n$ & $n$ & $\eta$ & $n$ & 0,20 & $n$ & 4 & Tag. & $n$ & 0,10 . & , & \\
\hline 14.20 & $\eta$ & 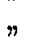 & $n$ & $n$ & $"$ & 0,30 & $\eta$ & 12 & " & $"$ & 0,10 . & $n$ & \\
\hline 15. 3 & 7 & $n$ & $"$ & $n$ & $\eta$ & 0,40 & $\eta$ & 14 & $\pi$ & $n$ & 0,10 . & $"$ & \\
\hline 15. 3 & " & $"$ & $n$ & $"$ & $n$ & 1,25 & $"$ & 13 & Woch. & . ” & $0,05-0,10$ & $n$ & \\
\hline 29. 3 & $"$ & $"$ & $n$ & $n$ & $"$ & 0,50 & n & 15 & $\eta$ & $"$ & 0,05 . & 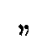 & \\
\hline 18. 3 & $\eta$ & $n$ & $\eta$ & $\eta$ & $n$ & 0,60 & $r$ & 3 & $"$ & $n$ & 0,10 . & & \\
\hline 13. 4 & ” & $n$ & $n$ & $\eta$ & $"$ & 0,40 & $n$ & 17 & Tag. & $n$ & 0,10 . & $"$ & \\
\hline 20. 4 & n & $n$ & $n$ & $n$ & $n$ & 1,00 & $\eta$ & 4 & Mon. & $n$ & $0,05-0,10$ & & \\
\hline 21. 4 & $n$ & $n$ & $\eta$ & $"$ & $n$ & 0,50 & $\pi$ & 3 & $"$ & 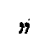 & $0,05-0,10$ & & \\
\hline 22,4 & $n$ & $n$ & $n$ & $n$ & $n$ & 0,50 & $\eta$ & 6 & Woch. & . & $0,05-0,10$ & $n$ & \\
\hline 8. 4 & $n$ & $n$ & $n$ & $\eta$ & $n$ & 1,10 & $n$ & 7 & & $n$ & 0,05 & $n$ & \\
\hline
\end{tabular}


$\mathrm{Nr}$.

32. 4 Woch. n. Inj. v. Hg. sal. 0,10

u. Th. ac. Hg. 0,15 innerh. 4 Woch. in Dos. 0,05-0,10 Q.-M. 4

30.

28. 6

28. 6

1.

15. $6 \frac{1}{2}$ " $" n$ " $" 0,40$ " 14 Tag.

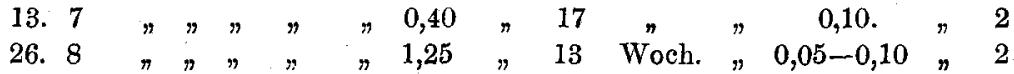

\section{Analysen mit negativem Resultat nach mehreren}

\section{Injectionen.}

30. 11 Std. n. Inj. v. Hg. sal. 0,10

u. Th. ac. Hg. 0,05 innerh. 10 Tag. in Dos. 0,05. Kein Q.

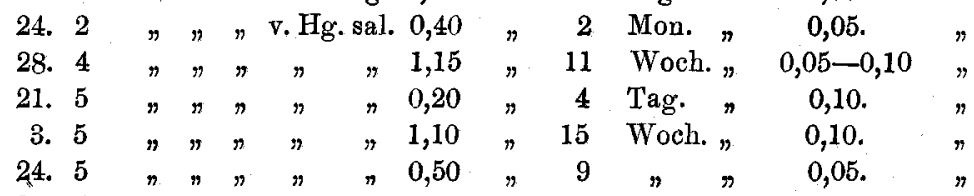

32. $5 " n " n, 0,10$

Th. ac. Hg. 0,05

30. $6 " \quad n$ v. Hg. sal. 0,10

12 Tag. " 0,05 .

Th. ac. Hg. 0,05

16. 7 " "v. Hg. sal. 0,75

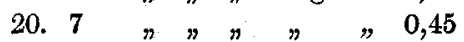

32. 7 " " " $"$ : 0,10

Th. ac. Hg. 0,10

20. 8 " " v. Hg. sal. 0,90

20. 8

24. 8

25. 8

, 0,45

$\eta$

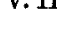

" 0,35

15. 9

9. $" n$

0,25

26. 9

\%. $n \pi$

\%. $" \#, \quad " \quad n \quad 0,20$

29.11

29.14

$" n$

0,20

$n " \Rightarrow \quad " \quad \Rightarrow, 10$

14.18

$n n$

0,25

10

10 " "

0,05 .

$51 / 2$ Woch. "

$0,05-0,10$

$0,05-0,10$ "

13.

$" n$

24. 3

$"$,

25. 3 Woch. ,

7. $3^{1 / 2}, n$

0,30

0,40

0,30

0,20

23. $31 / 2 " n " n$

28. 4

14. 5

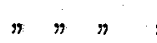

" 0,80

. 2,25

1,80

18 Tag. ,

0,05 .

$3 \frac{1}{2}$ Mon. "

$4 \frac{1}{2}$,

$0,05-0,10$

7 Woch."

$61 / 2 " n$

$0,05-0,10 \quad$ "

10 Tag. "

0,05 .

0,05 .

$5 \%$.

0,10 .

0,05 .

0,05 .

4 "Woch."

0,05 .

12 Tag. "

0,10 .

17

4 Woch."

0,10 .

16 Tag.

0,05 .

0,05 .

7 Woch."

0,10 .

$61 / 2$ Mon. "

0,10 .

$5 \frac{1}{2} " \Rightarrow$

$0,05-0,10$

12 Tag. "

0,10 . 
Untersuchungen über d. Resorption u. Eliminat. des Quecksilb. 217 Nr.

20. 5 Woch. n. Inj. v. Hg. sal. 1,00 innerh. $t$ Mon. in Dos. 0,05-0,10 Kein Q.

21. $5 " \# " \# " 0,10,1$ Woch. " $0,05$.

22. $50 " n " n, " 0,50$ "

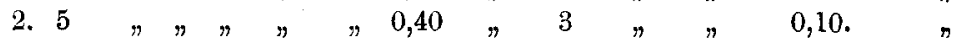

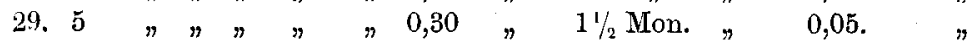

26. $5 " \# "$ " " $" 1,25 " 13$ Woch. " $0,05-0,10$ "

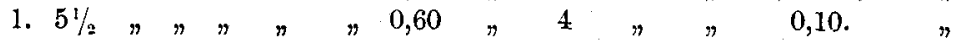

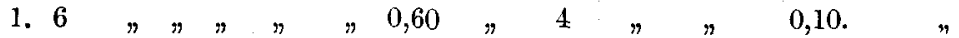

13. 6 6 " " $" ~ " 0,15$ " 5 Tag. $" 0,05-0,10 "$

26. $6 " \# "$ " $" 0,25 ", 6$ Woch. " 0,05 . "

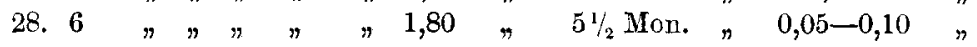

32. 6 " $" \#, " n, 10$

u. Th. ac. Hg. $0,15, \quad 4$ Woch. " 0,05 . "

29. $61 / 2 " \#$ " $"$ v. Hg. sal. $0,50 \# 15 \quad " \quad " \quad 0,05$.

1. 7 " " " " 1,78 " 4 Mon. " $0,10.4$

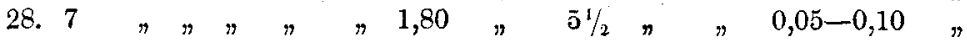

18. 8 " " " " $0,60 " 3$ Woch. " 0,10 . "

23. 8 " " " $" \quad 2,25 \quad " 61 / 2$ Mon. " $\quad 0,10$. "

26. 8 " " " " $0,25 " 6$ Woch. " $0,05 . \quad$ "

i. $9 " \# " \#, 0,60$ " $" 4$ " $" 0,10$.

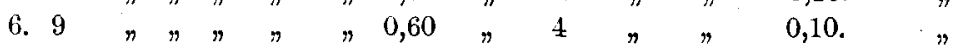

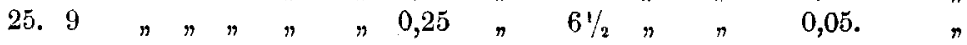

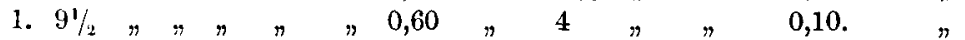

$23.10 " \# " \quad " 2,25 \quad$ " $\quad 6 \frac{1}{2}$ Mon. " 0,10 . "

$2.12 ", ", \quad " 0,40 " 3$ Woch. " $0,10 . \quad$ "

$26.13 \quad " \quad " \quad$ " $\quad 1,25 \quad$ " $13 \quad$ " $\quad 0,05-0,10$ "

$15.15 \quad ", " \quad, 0,40$ " 14 Tag. " $0,10 . \quad$ "

12. $3 \frac{1}{2}$ Mon., " " $0,80 " 8$ Woch. " $0,10 . \quad$ "

13. $4 \frac{1}{2} " n " n, 0,15, \quad 5$ Tag. " $0,05-0,10 "$

19. $5 \frac{1 / 2}{2} ", \quad n \quad, 0,40 \quad " 3$ Woch. " $0,10 . \quad$ "

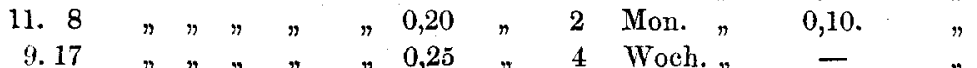

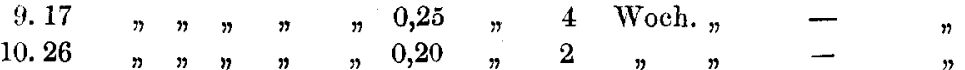

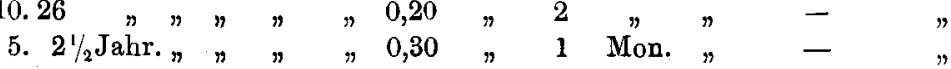

Quecksilberanalysen an Harn, mit positivem Resultat, nach mehreren Injectionen, sind an Zahl 100. In dieselben sind 7 Untersuchungen nach Injection ron Thymol. acet. Hg. eingeschlossen; ich habe nicht gezögert sie mit den übrigen zusammenzustellen, um so mehr, als kein wesentlicher Unterschied in diesen Analysen im Vergleich zu den nach Hg.-salicyl. zu bemerken ist. 
In 2 Analysen, die eine 1 Stunde, die zweite 4 Stunden nach der letzten Injection ausgeführt, fand sich Quecksilber in sehr grosser Menge und das obgleich in einem Falle die Dosis nur 0.05 betrug.

In 10 Analysen, an 6 Fällen innerhalb 12 Stunden nach der letzten Injection gemacht, war in 6 Fällen die Quecksilbermenge hoch, in 4 Fällen niedrig. Wo die Quecksilbermenge geringer war, hatte die Dosis in 3 Fällen nur 0.05 betragen.

12-24 Stunden nach der letzten Injection sind 9 Analysen an 8 Patienten gemacht worden und war die Quecksilbermenge nur in einer Analyse, in welchem Falle die letzte Injection 0.05 betragen hatte, gering, in allen anderen Fällen sehr hoch.

Am 2. Tage nach der letzten Injection gaben 13 Analysen aus 5 Fällen eine hohe Quecksilbermenge; in 4 Analysen war sie gering. Von diesen letzteren waren 3 an demselben Falle ausgeführt und die 4. nach einer Injection von 005 , wobei die nächst vorhergehende Injection 12 Tage früher gemacht worden war.

Harnuntersuchungen während des 5. bis 7. Tages incl. nach der letzten Injection sind 18 an Zahl. Von diesen ergaben 13 Analysen geringe Quecksilbermenge und 5 Analysen hohe.

Innerhalb der zweiten Woche nach der letzten Injection sind 21 Analysen gemacht worden und von diesen war in 6 Fällen die Quecksilbermenge hoch und in 15 Fällen niedrig; von 9 Injectionen zu 0.05 haben nur 2 eine grössere Quecksilbermenge zur Folge gehabt.

In der 3. und 4. Woche nach der letzten Injection haben von 16 Analysen nur 2 hohe Quecksilbermenge erwiesen, 14 dagegen geringe.

Während der 6. und 7. Woche nach der letzten Injection sind 5 Untersuchungen ausgeführt worden; in diesen konnte Quecksilber in geringerer. Menge nachgewiesen werden, ebenso bei einer Untersuchung, nach 8 Wochen. In Fällen, wo das Quecksilber noch längere Zeit nach der letzten Injection im Urine anzutreffen war, war gewöhnlich eine grössere Quantität in verhältnissmässig kurzer Zeit injicirt worden. 
In 60 Analysen, wo mehrere Injectionen derselben vorausgegangen waren, konnte kein Quecksilber im Harne nachgewiesen werden.

Die Analysen waren in diesen Fällen gemacht: in 1 Falle innerhalb 11 Stunden nach der letzten Injection,

\section{1}

9 Fällen

8

7

13

6

8

7 des

$" 4 . "$ " $"$

$\begin{array}{lll}" & " & " \\ " & n & " \\ " & " & " \\ " & " & " \\ " & " & " \\ " & n & "\end{array}$

Aus diesen Fällen ist ersichtlich, dass während der 7 ersten Tàge nach der letzten Injection, wo das Quecksilber mit grösster Wahrscheinlichkeit im Harne noch hätte müssen angetroffen werden können, dasselbe in 11 Fällen fehlte.

Prüft man diese Fälle aber näher, so ergibt sich, dass im ersten Falle, der sich auf Nr. 30 bezieht, eine $61 / 2$ Stunden früher gemachte Analyse positive Resultate ergab und also anzunehmen ist, dass das Quecksilber sich auch bei der späteren Analyse vorfand, aber aus irgend einer Veranlassung im Harne nicht nachzuweisen war.

In Nr. 3, wo das Quecksilber 5 Tage nach der Injection verschwunden war, ist die Erklärung vielleicht im niedrigen spec. Gewicht 1.005 des Urines zu suchen.

In 8 Fällen betrug die Dosis nicht nur in der letzten Injection, sondern auch bei der überwiegenden Zahl der früheren nur 0.05, oder auch wurden die Injectionen mit langen Zwischenräumen gemacht.

In Nr. 20, wo das Quecksilber 7 Tage nach der Injection verschwunden war, war der Zeitraum $5 \frac{1}{2}$ Wochen, in dem 0.45 injicirt wurden, verhältnissmässig lang, auch war ausser bei den beiden letzten Injectionen die kleinere Dosis angewandt worden.

Innerhalb der zweiten Woche, wo man: füglich auch erwarten konnte, Quecksilber im Harne zu finden, fehlte es in 8 Analysen: Von diesen betrug in 7 Fällen die letzte Injection 
0.05 und wurden die vorhergehenden Injectionen mit langen $Z$ wischenräumen gemacht, und war überhaupt die Totalquantität des Injectionsstoffes klein im Vergleich zur Zeit, in der die Injectionen gemacht wurden. In Fall 15, dem einzigen, wo eine Menge von $0 \cdot 10$ injicirt wurde und der Urin 9 Tage nach der Injection quecksilberfrei war, kann dieses auf dem geringen spec. Gewicht 1.011 des Urines beruhen.

Während der 3. und 4. Woche nach der Injection wurden 7 Analysen ausgefïhrt und gaben ein negatives Resultat. Von diesen wurde in Nr. 14 die Untersuchung an nur $175 \mathrm{Grm}$. Urin gemacht; in Nr. 13 war 3 Wochen nach der Injection kein Quecksilber anzutreffen, doch beruhte dieses wohl auf irgend einem Zufall, denn sowohl 4 als $6 \frac{1}{2}$ Wochen nach der Injection konnte bei derselben Person Quecksilber nachgewiesen werden. In den beiden anderen Fällen Nr. 24 und $2 \tilde{5}$. die 3 Wochen nach der Injection untersucht wurden, war eine Einspritzung von nur 0.05 gemacht worden. In 3 Fällen fehlte das Quecksilber 31/2 und 4 Wochen nach der Injection.

Während der 5. und 6. Woche nach der letzten Injection wurden 13 Analysen gemacht und während der 7. und 8. Woche 7, ohne dass Quecksilber im Urine anzutreffen war. Dasselbe war der Fall in 15 Analysen, die 9 Wochen bis $8 \%$ Monat nach der letzten Injection gemacht wurden.

Fasst man die Resultate der positiven sowohl wie auch der negativen Analysen zusammen, so findet man, dass das Quecksilber, wo es sich nach einer vorhergehenden Injection schon zu vermindern begann, einige Stunden nach erneuerter Injection wieder in sebr grosser Menge im Harne auftritt, sich dann während des ersten und zweiten Tages recht hoch erhält und dass gewöhnlich nur nach Injection der kleineren Dosis von 0.05 die Quecksilbermenge gering war. So hat ron 20 während des ersten Tages nach der letzten Injection gemachten Analysen nur eine negatives Resultat gegeben. Auch während des zweiten Tages hielt sich die Quecksilberquantität hoch; von sämmtlichen in dieser Zeit gemachten Analysen, 14 an der Zahl, hat nur eine Untersuchung nach Injection von 0.05 negatives Resultat gegeben. Während des 3. und 4. Tages zeigt das Quecksilber die Tendenz abzunehmen, hält sich aber 
doch noch verhältnissmässig hoch; von 8 Analysen aus diesen Tagen ist nur eine mit negativem Resultat vorgekommen. Erst am Schluss der ersten Woche tritt eine bestimmte Verminderung ein und in dieser Zeit gaben schon $\delta$ Analysen von 26 ein negatives Resultat. Auch während der zweiten Woche wurde in 29 Analysen 8mal negativer Befund erhalten. Die negativen Resultate ergaben sich im Allgemeinen nach Injection der kleineren Dosis von 0.05 , in einigen Fällen hat möglicherweise auch das niedrige spec. Gewicht des Harnes dazu beigetragen.

In der dritten und vierten Woche nach der letzten Injection ergaben die Analysen in der überwiegenden Anzahl Fälle, nämlich 16 von 23 , ein positives Resultat, wenn auch die Quecksilbermenge hauptsächlich gering war; nur in 2 Fällen war sie hoch.

Auch von den während der 5. bis 8 . Woche ausgeführten Untersuchungen, 25 an der Zahl, gaben 6 Analysen ein positives Resultat mit geringem Quecksilbergehalt im Harne, 19 Analysen dagegen ein negatives. Die übrigen 15 Analysen, 9 Wochen bis $2 \%$ Jahre nach der letzten Injection ausgeführt, gaben alle ein negatives Resultat.

Vergleicht man die Resultate dieser letztgenannten Analysen mit den nach nur einmaliger Injection erhaltenen, so findet man während der ersten und auch im Beginn der zweiten Woche eine unverkennbare Uebereinstimmung. Nach der letzten Injection steigt die Quecksilberquantität im Harne recht schnell bis zum 3. und 4. Tage, wo sie abzunehmen beginnt; diese Verminderung zeigt sich am Ende der ersten und während der zweiten Woche deutlich fortschreitend. Erst während der 3. und 4. Woche, wo das Quecksilber nach einer einfachen Injection verschwunden ist, tritt der Unterschied am auffallendsten hervor, da es dann, wenn auch in geringer Menge, gewöhnlich noch vorkommt und noch während der 6., 7. und 8. Woche nach beendigter Injectionscur anzutreffen ist.

Wo also eine grössere Menge $\mathrm{Hg}$. salicyl. in verhältnissmässig kurzer Zeit dem Körper zugeführt ist, bleibt es im Vergleich zu seiner Remanenz nach einer einfachen Injection 
viel längere Zeit zurück und kann bisweilen sogar noch am Ende des zweiten Monates im Harne nachgewiesen werden.

Ich gebe hier eine Uebersicht über das Verhältniss der positiven und negativen Analysen zu einander während der verschiedenen Perioden nach Abschluss der Injectionen.

\begin{tabular}{|c|c|c|c|}
\hline $\begin{array}{c}\text { Anzahl der } \\
\text { Analysen }\end{array}$ & $\begin{array}{l}\text { Zeit } \\
\text { nach der } \\
\text { letzten } \\
\text { Injection }\end{array}$ & $\begin{array}{c}\text { Anzahl der Fälle, } \\
\text { in denen } \\
\text { der Harn Quecksilber } \\
\text { enthielt }\end{array}$ & $\begin{array}{l}\text { Anzahl der Analysen } \\
\text { mit } \\
\text { quecksilberfreiem Urin }\end{array}$ \\
\hline 68 & 1 Woche & $57=83,8 \%$ & $\left.11^{1}\right)=16,2^{\%}$ \\
\hline 29 & 2 Wochen & $21=72,4 \%$ & $\left.8^{2}\right)=27,6 \%$ \\
\hline 13 & $3 \quad n$ & $9=69,2 \%$ & $\left.4^{3}\right)=30,8 \%$ \\
\hline 10 & 4 & $7=70,0 \%$ & $3=30,0 \%$ \\
\hline 5 & 5 & $0_{1}$ & 7 \\
\hline 9 & 6 & & $61-760$ \\
\hline 7 & 7 & $2=24 \%$ & $3\}=76 \%$ \\
\hline 4 & 8 & 1) & 3) \\
\hline \multirow[t]{4}{*}{15} & $9 \quad "$ & 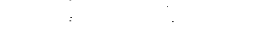 & \\
\hline & bis & & \\
\hline & $2^{1 / 2}$ Jahre & 0 & $15=100 \%$ \\
\hline & & & \\
\hline
\end{tabular}

Bei Beantwortung der Frage, ob das Quecksilber nach Injection von $\mathrm{Hg}$. salicyl. constant eliminirt wird oder ob die Ausscheidung mit längeren oder kürzeren Intervallen vor sich geht, so kann nach dem schon Erwähnten und bei einem Blick auf die Analysen unbedingt gesagt werden, dass dasselbe im Verhältniss zur zugefürten Menge und ununterbrochen ausgeschieden wird, so lange noch etwas im Organismus vorhanden ist.

1) In 8 Fällen betrug die Injectionsdosis nur 0,05 ; in 1 Falle war das spec. Gewicht des Harnes ungewöbnlich niedrig, 1,005; in 1 Falle war in langer Zeit nur eine geringe Quecksilbermenge injieirt und 1 F'all enthielt wahrscheinlich, wie schon hervorgehoben, Quecksilber wenn es auch nicht nachgewiesen war.

2) In 7 Fällen letzte Injection nur 0,05, und im 1 Falle spec. Gewicht des Harnes 1,011.

3) In 2 Fällen letzte Injeotion nur 0,05 , und in 1 Fall wurde die Analyse mit nur $175 \mathrm{Cm}$. Urin gemacht. 
Die 6 Fälle Nr. 13, 14, 15, 23, 26 und 32, wo nach einer negativen Analyse später wieder Quecksilber im Urine anzutreffen war, sind an Zabl zu gering, um eine Bedeutung zu haben; es fand sich wahrscheinlich auch in diesen Analysen Quecksilber, jedoch in so minimaler Quantität, dass es durch das Mikroskop nicht nachzuweisen war.

Nur 8 Untersuchungen an 4 Fällen sind nach Calomelinjectionen gemacht worden und zwar alle erst lange Zeit nach Injection einer relativ geringen Quantität, weshalb auch bestimmte Schlusssätze mit Bezug auf diese Fälle nicht zu ziehen waren. So ergaben in $\mathrm{Nr} .5,2 \frac{1}{2}$ Jahre nach Injection ron zusammen 0.30 , in Nr. 9, 17 Monate nach Injection ron $0 \cdot 25$, in $\mathrm{Nr}$. 10, 26 Monate nach Injection von 0.20 , und in Nr. 11, 8 Monate nach Abschluss der Cur, alle Analysen ein negatives Resultat.

Nach Inunction s cur sind 21 Analysen an 8 Fällen ausgeführt worden. In Nr. 3 begann das Schmieren nur 11 Tage nach einer recht energischen Injectionscur und fand sich dann wahrscheinlich noch Quecksilber im Harne vor, da die Analyse 9 Tage früher ein positives Resultat ergeben hatte. Es wurden 7 Analysen gemacht und während der ganzen Zeit der Schmierungen positive Resultate erhalten. 18 Tage nach Einreibung von 50 Päckchen war das Quecksilber aus dem Harne verschwunden. Dieses negative Resuitat beruhte wohl auf dem niedrigen spec. Gewicht 1.005 des Harnes, zumal da noch 24 und 26 Tage nach beendigter Schmiercur Quecksilber ausgeschieden wurde.

Aus Nr. 23 geht herror, dass nach Einreibung von 7 Päckchen noch kein Quecksilber im Urine nucbzuweisen war, und 14 Tage nachdem 10 Päckchen eingerieben waren, nur eine geringe Menge angetroffen werden konnte.

In Nr. 31 waren 12 Analysen gemacht worden, nach Einreibung von 2, 4, 6, 8, 13 und 16 Päckchen, alle mit negativem Resultat; erst nach Einreibung von 19 Päckchen, oder 23 Tage nach Beginn der Cur war Quecksilber im Urin anzu. treffen; 9 Tage nach Beendigung der Behandlung war es wieder verschwunden. Nach einer Pause von 2 Wochen wurden wieder 4 Einreibungen gemacht und 11 Tage darauf fand sich viel 
Quecksilber; 20 Tage nach abgeschlossener Behandlung war er wieder verschwunden. Hieraus ist ersichtlich, dass nach der Schmiercur das Quecksilber viel später im Harne auftritt als nach der Injectionscur. Wie viel Quecksilber durch die Haut resorbirt wird, beruht natürlich zum grossen 'Theil darauf, wie die Einreibung ausgeführt wird; da diese nun im erwähnten Falle sehr sorgfältig während einer halben Stunde gemacht wurde, so dürfte die Ursache für das langsame Auftreten und sehnelle Verschwinden des Quecksilbers nicht daran liegen, sondern würde ich eher mit Nega annehmer, dass dasselbe durch die Haut ungleichmässig und langsam aufgenommen und ausgeschieden wird.

Obgleich die Anzahl dieser Analysen zu gering ist, um in Bezug auf die Resorption und Elimination des Quecksilbers einen Vergleich mit den Untersuchungen nach der Injectionscur zu rechtfertigen, so sind sie doch nicht ohne eine gewisse Bedeutung beim Constatiren des Zeitpunktes für das erste Auftreten des Quecksilbers im Harne nach der Inunctionsbehandlung; in dieser Hinsicht liegen auch relativ mehr Analysen vor, welche mit früheren Untersuchungen darin übereinstimmen, dass das Quecksilber nach der Inunctionscur weit später im Urin auftritt als nach der Injectionsbehandlung. Was die Remanenz des Quecksilbers betrifft, so hat dasselbe, wenn es erst einmal im Harve auftrat, während der ganzen Behandlung und nach einer kräftigeren Cur wenigstens noch 4 Wochen später nachgewiesen werden können.

Nach interner Behandlung sind 30 Analysen an 5 Fällen gemacht worden. Die zur Anwendung gekommenen Präparate waren Hg. salicyl., Pil. Hg. oxydul. oder Pil. protojod. Hg. In einem Theil Fälle, wie Nr. 19 und Nr. 20, war die Behandlungszeit recht kurz, nur 5 und 10 Tage, was wohl auch der Grund dafür war, dass schon 4 und 11 Tage nach Schluss der Behandlung das Quecksilber nicht mehr anzutreffen war; auch in Nr. 4, wo die Analysen 4 und 5 Wochen nach beendigter Cur ein negatives Resultat gaben, dauerte die Behandlung nur 7 Tage. In diesem Falle fand sich doch trotz der kurzen Behandlungszeit noch 9 Tage nach Schluss derselben Quecksilber im Urine. In Nr. 17, wo die Behandlung 
2 Wochen dauerte, war das Quecksilber schon 1 und 2 Wochen nach Beendigung der Cur verschwunden, doch war auch die angewandte Quecksilberquantität in der letzten Zeit der Be. handlung ganz gering, nur $0.03 \mathrm{Hg}$. salicyl.

Der Fall Nr. 27, wo die Behandlung am längsten währte, 1 Monat, zeigte noch 19 Tage nach abgeschlossener Behandlung Quecksilber im Harn, das jedoch nach 6 und 11 Wochen verschwunden war.

Was nun den frühesten Zeitraum für das Auftreten des Quecksilbers im Urine nach interner Behandlung betrifft, so zeigen die Fälle Nr. 17 und 19 ganz übereinstimmende Resultate. In beiden Fällen hatten die Analysen die 5 ersten Tage negative Resultate ergeben, erst am 6 . und den darauf tolgenden Tagen positive; auch die in Nr. 4 am 5. Tage nach Beginn der Behandlung gemachte Analyse lieferte ein positives Resultat. In Nr. 17 und 19 gaben die während der Behandlung selbst gemachten Analysen negative Resultate, trotzdem schon sinige Male Quecksilber im Harne hätte nachgewiesen werden können.

Nach combinirter Quecksilberbehandlung ${ }^{1}$ ) sind nur 11 Analysen an 7 Fällen gemacht worden und sind die Resultate derselben in der Hauptsache mit denen der Analysen nach einfacher Quecksilberbehandlung übereinstimmend. So wurden nur in zwei Fällen, Nr. 7 und 25, positive Resultate erhalten, im ersten Falle ungefähr 2 Wochen nach einer 2 wöchentlichen Inunctions- und internen Behandlung und im zweiten Falle 4 Wochen nach einer 2monatlichen Cur ron Deutojod. Hg. innerlich und darauf folgender Injection von Hg. salicyl. 0.20.

In den 9 Fällen, wo die Analysen negative Resultate gaben, war eine längere Zeit seit dem Abschluss der Behandlung verstrichen, nämlich von 9 Wochen bis 10 Monaten. Nur in Nr. 27 war das Resultat der Analysen negativ, trotzdem nur 1 Woche seit der Behandlung verflossen war. Hierbei ist zu bemerken, dass die Injectionen von $\mathrm{Hg}$. salicyl. 0.30 zuerst

1) Injection von Calomel oder $\mathrm{Hg}$. salicyl. combinirt mit Inunctionsoder jnterner Behandlung. 
innerhalb 2 Wochen gemacht und in den letzten Wochen die Pillen genommen wurden.

Aus dem Gesagten können folgende Schlüsse gezogen werden:

Bei einer Quecksilbercur wird das Quecksilber so lange regelmässig ausgeschieden, als es sich im Organismus vorfindet.

Die Menge des ansgeschiedenen Quecksilbers hängt von der zugeführten Quecksilbermenge und der. kürzeren oder längeren Zeit, die seit Abschluss der Behandlung vergangen ist, ab.

Nach einer einmaligen Injection von Hg. salicyl. tritt das Quecksilber sehr schnell, schon nach einigen Stunden, im Harne auf, findet sich dann während des ersten und zweiten Tages in grosser Menge vor, nimmt wieder schnell ab und ist gewöhnlich schon am Anfang der zweiten Woche aus dem Harne verschwunden.

Nach einer Injectionscur, oder wenn eine grössere Menge Hg. salicyl. in verhältnissmässig kurzer Zeit injicirt wurde, kann Quecksilber bedeutend längere Zeit im Harne nachgewiesen werden als nach einer einfachen Injection; die Quecksilbermenge hält sich hoch bis Ende der ersten Woche, wo sie abzunehmen beginnt, wo sie aber auch bisweilen nach Injection der kleineren Dosis von 0.05 schon fehlen kaun. Während der darauf folgenden Wochen schreitet die Verminderung fort, doch kann noch in $70 \%$ während der 4 . Woche Quecksilber angetroffen werden, im zweiten Monate hingegen nur in $24 \%$ aller Analysen.

Nach einer In unctions cur tritt das Quecksilber viel später im Harne auf als nach einer Injectionscur, erst nach 1- bis 2 wöchentlicher Behandlung, fand sich aber nach seinem Auftreten während der ganzen Behandlungszeit und konnte noch wenigstens 4 Wochen nach der Behandlung nachgewiesen werden. 
Nach interner Behandlung trat das Quecksilber auch bedeutend später im Harne auf als nach Injectionscur, erst am 5. und 6. Tage und in bedeutend geringerer Menge und konnte noch 19 Tage nach Abschluss der Behandlung angetroffen werden.

Da die meisten Quecksilberpräparate bei Injection in die Gewebe durch die Eiweisscoagulation, welche sie verursachen, eine bedentende Reizung hervorrufen, woraus dann grössere oder geringere Infiltrationen und oft genug ausgebreitete Abscesse entstehen können, so betont Liebreich ${ }^{1}$ ) die Nothwendigkeit bei Quecksilberinjectionen nur solche Präparate zu wählen, die in den Geweben keine Verbindungen eingehen, oder nur leicht lösliche. Diese Eigenschaft, die Leichtlöslichkeit, scheint das Hg. salicyl. vor anderen Präparaten zu besitzen, denn durch Experimente ist dargelegt, dass es in keiner Concentration Eiweiss zum Coaguliren brachte, wogegen es sich in Kochsalzlösung aufgelöst hält. Da sich nun überall im Organismus Chlornatrium findet, wird das $\mathrm{Hg}$. salicyl. durch dasselbe wahrscheinlich in Lösung gebracht und kommt dadurch schnell zur Resorption.

Die klinische Erfahrung hat auch zur Genüge die Richtigkeit dessen bestätigt, dass wir im Hg. salicyl. ein werthvolles Präparat besitzen, welches ebenso schnell wie die löslichen Präparate resorbirt wird, ohne jedoch eine wesentliche Reizung in den Geweben hervorzurufen. Die Reizung war nämlich in den meisten Fällen minimal, wo Infiltrationen auftraten, waren sie von geringer Bedeutung und nie von Abscessen gefolgt. Die schnelle Resorption gab sich durch Salivation zu erkennen, die häufig schon 1 Stunde nach der Injection auftreten konnte und durch die schnelle Veränderung der Symptome, welche manchmal schon am zweiten Tage deutlich sichtbar war. Wenn sich auch verschiedene Ansichten über den Vortheil einer schnelleren oder langsameren Ausscheidung des Quecksilbers geltend gemacht haben, so dürfte doch die schnelle Absorption und darauf folgende schnelle

1) Die Behandlung der Syphilis mit mercurialen Injectionen. Vierteljahresschrift f. Derm. und Syphilis. 1884. 
Ausscheidung wahrscheinlich Ursache dafür sein, dass mir nie Symptome von Hydrargyrose zur Beobachtung kamen, ungeachtet recht langer Injectionscuren mit Dosen von $0 \cdot 10$.

Um eine möglichst schnelle und dauernde Wirkung zu erhalten, ohne eine Hydrargyrose hervorzurufen, habe ich es am vortheilhaftesten gefunden, das $\mathrm{Hg}$. salicyl. in Dosen von 0.10 anzuwenden und die ersten 3-4 Injectionen mit Pausen von 4-5 Tagen zu machen, die späteren mit Intervallen von 7-9 Tagen.

Helsing fors, im December 1891. 